\title{
Large Earthquakes in the Macquarie Ridge Complex: Transitional Tectonics and Subduction Initiation
}

\author{
Larry J. RufF, ${ }^{1}$ Jeffrey W. Given, ${ }^{2}$ Chris O. Sanders ${ }^{3}$ and \\ CHRISTINE M. SPERBER ${ }^{1}$
}

\begin{abstract}
While most aspects of subduction have been extensively studied, the process of subduction initiation lacks an observational foundation. The Macquarie Ridge complex (MRC) forms the Pacific-Australia plate boundary between New Zealand to the north and the Pacific-Australia-Antarctica triple junction to the south. The MRC consists of alternating troughs and rises and is characterized by a transitional tectonic environment in which subduction initiation presently occurs. There is a high seismicity level with 15 large earthquakes $(M>7)$ in this century. Our seismological investigation is centered on the largest event since 1943: the 25 MAY 1981 earthquake. Love, Rayleigh, and $P$ waves are inverted to find: a faulting geometry of right-lateral strike-slip along the local trend of the Macquarie Ridge $\left(\mathrm{N} 30^{\circ} \mathrm{E}\right)$; a seismic moment of $5 \times 10^{27} \mathrm{dyn} \mathrm{cm}\left(M_{W}=7.7\right)$; a double event rupture process with a fault length of less than $100 \mathrm{~km}$ to the southwest of the epicenter and a fault depth of less than $20 \mathrm{~km}$. Three smaller thrust earthquakes occurred previous to the 1981 event along the 1981 rupture zone; their shallow-dipping thrust planes are virtually adjacent to the 1981 vertical fault plane. Oblique convergence in this region is thus accommodated by a dual rupture mode of several small thrust events and a large strike-slip event. Our study of other large MRC earthquakes, plus those of other investigators, produces focal mechanisms for 15 earthquakes distributed along the entire MRC; thrust and right-lateral strike-slip events are scattered throughout the MRC. Thus, all of the MRC is characterized by oblique convergence and the dual rupture mode. The "true" best-fit rotation pole for the Pacific-Australia motion is close to the Minster \& Jordan RM2 pole for the Pacific-India motion. Southward migration of the rotation pole has caused the recent transition to oblique convergence in the northern MRC. We propose a subduction initiation process that is akin to crack propagation; the 1981 earthquake rupture area is identified as the "crack-tip" region that separates a disconnected mosaic of small thrust faults to the south from a horizontally continuous thrust interface to the north along the Puysegur trench. A different mechanism of subduction initiation occurs in the southernmost Hjort trench region at the triple junction. Newly created oceanic lithosphere has been subducted just to the north of the triple junction. The entire MRC is a "soft" plate boundary that must accommodate the plate motion mismatch between two major spreading centers (Antarctica-Australia and Pacific-Antarctica). The persistence of spreading motion at the two major spreading centers and the consequent evolution of the three-plate system cause the present-day oblique convergence and subduction initiation in the Macquarie Ridge complex.
\end{abstract}

Key words: Earthquakes, seismotectonics, subduction initiation, soft plate boundary.

${ }^{1}$ Department of Geological Sciences, University of Michigan, Ann Arbor, MI 48109, U.S.A.

2 Sierra Geophysics, Kirkland, WA 98033 , U.S.A.

${ }^{3}$ Seismological Laboratory, California Institute of Technology, Pasadena, CA 91125, U.S.A. (now at USGS, Menlo Park, CA 94025). 


\section{Introduction}

Subduction zones consume oceanic lithosphere and are an indispensible part of plate tectonics. Unlike the oceanic lithosphere production system which can be linked as a nearly continuous, albeit sinuous, strand around the earth, subduction zones are a rather dissociated group and are found in several isolated corners of the world. While plate tectonics can predict that subduction zones are required along certain plate boundaries, it does not stipulate how subduction zones initiate and develop. The preservation of newly created oceanic lithosphere and the propensity for spreading centers to fragment continents leaves a wealth of geological information on the initiation and evolution of spreading. On the other hand, the subject of subduction initiation has little observational basis. To find such observations, we need to look at some muddled tectonic regimes. The Macquarie Ridge complex presents a natural laboratory for studies of subduction initiation.

\section{Tectonics of the Macquarie Ridge Complex}

The Macquarie Ridge complex is a complicated physiographic feature that trends approximately north-south between South Island, New Zealand and the Pacific-Antarctica spreading center. This feature consists of a sequence of troughs and ridges, with Macquarie Island as the only exposed expression. The seismically active Macquarie Ridge complex (hereafter: MRC) is crudely continuous with the Tonga-Kermadec-New Zealand seismic activity. The basic physiographic features and seismicity of the MRC are shown in Figure 1. The earthquake epicenters generally cluster about the bathymetric expression of the MRC. The high level of seismic activity, 15 events with $M_{s}>7$, clearly suggests that the $\mathrm{MRC}$ is the active plate boundary between the Pacific and India plates. In the past, there has been some confusion over the nature of this plate boundary. Various authors have referred to the $\mathrm{MRC}$ as: a spreading ridge, a convergent plate boundary, a strike-slip margin, or some combination of the above. Global plate tectonic models place the rotation pole between the Pacific and India plates close to the MRC, therefore the relative plate motion can change rapidly along the $\mathrm{MRC}$. The rotation pole from the global model RM2 (MINSTER and JORDAN, 1978) is plotted in Figure 1. The relative motions along the MRC predicted by this pole are depicted by the velocity vectors. Scattered intermediate-depth earthquakes beneath the southwestern corner of South Island provide evidence for convergence in this region (see SCHOLz et al., 1973).

Minster and Jordan treated the entire India-Australia region as one plate. Several observations suggest that there is some decoupling between India and Australia of a transform nature along the trend of the Ninety-East Ridge (STEIN and OKAL, 1978; WIENS et al., 1985). Since the MRC is at the eastern edge of the 


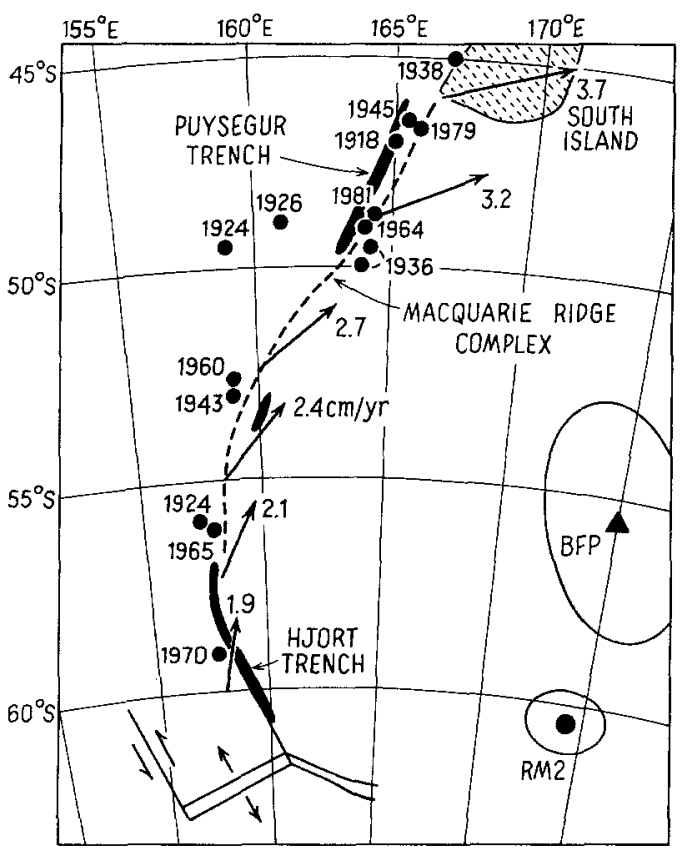

Figure 1

Simplified tectonics and seismicity of the Macquarie Ridge complex. Large earthquakes (magnitude greater than 7) are plotted as dots with the year of their occurrence. Two Pacific-Australia plate motion rotation poles and their error ellipses are plotted: the best-fitting pole (BFP) and the global model pole (RM2) from MinSTER and JoRDAN (1978). The motion of the Australia plate relative to the Pacific plate along the Macquarie Ridge is shown by the vectors, based on the RM2 pole with velocity in $\mathrm{cm} / \mathrm{yr}$. The bathymetric rise of the Macquarie Ridge is schematically plotted as the dashed line, while the troughs are indicated by the solid regions. The spreading segment and Balleny transform fault between the Antarctica and Australia plates are also sketched. The Pacific-Antarctica-Australia triple junction is located at $61 \frac{1}{2}^{\circ} \mathrm{S} 161^{\circ} \mathrm{E}$.

India plate, the interaction along this boundary describes the relative motion of the Pacific plate (PAC) and the eastern part of the India plate, which includes Australia. Henceforth, we shall refer to the Australia plate (AUS) rather than the India plate when discussing the interaction along the MRC. The RM2 pole for the Pacific-India motions will be used as the initial PAC-AUS pole. The termination of the MRC at the Pacific-Antarctica spreading center results in a triple junction at this point. Hence, we shall eventually consider the interaction with the Antarctica plate (ANT).

Since the Pacific-Australia rotation pole is located close to the MRC, changes in the rotation pole location over geological time will be reflected in the evolution of the MRC. The plate tectonic reconstruction of MOLNAR et al. (1975) indicates that some type of spreading activity formed the entire MRC since the Oligocene (38 Ma). The change from a tensional to compressional environment implies that the rotation pole has migrated southward since the Oligocene (also see WALCOTT, 1978). The 
seismicity of South Island and the uplift of the South Island Alps are also consistent with a southward migration of the rotation pole, mostly since the Miocene (SCHOLZ et al., 1973). To summarize the basic geological setting, the MRC originally formed in an oceanic spreading center environment and subsequently served as a strike-slip plate boundary, with the northernmost part changing to a partly convergent boundary since the Miocene.

There are some inconsistencies in the geological setting that appear significant. In their comprehensive treatment of the magnetic lineations in this region, WEISSEL et al. (1977) noted that some oceanic crust appears to be missing; this crust was generated at the ANT-AUS spreading ridge segment at the PAC-ANT-AUS triple junction. It is noteworthy that this missing AUS plate crust is in the vicinity of the Hjort trench, a deep (maximum depth greater than $6 \mathrm{~km}$ ) arcuate trough. WeISSEL et al. (1977) offered two explanations for the missing crust: (1) it was subducted at the Hjort trench, and (2) the plate boundary jumped to the present location at the Hjort trench. WeIsSEL et al, then showed that the closure condition at the PAC-ANT-AUS triple junction implies subduction along the PAC-AUS boundary. RuFF and CAZENAVE (1985) addressed the possibility of subduction at the Hjort trench using SEASAT geoid anomalies and limited first motion data for the large 1924 earthquake; they concluded that subduction has probably occurred along the northern Hjort trench with Australia lithosphere subducting beneath the older Pacific lithosphere. If subduction has indeed occurred, note that newly created oceanic lithosphere has been subducted.

Another complication is the difference in the best-fitting and RM2 rotation poles (see Figure 1). The best-fitting pole is based only on the relative motion data along. the PAC-AUS plate boundary, while the RM2 pole results from the global inversion of all data. As discussed in MINSTER and JORDAN (1978), the adjustment of the PAC-AUS pole from the BFP to the RM2 location is mostly due to the requirement of PAC-ANT-AUS triple junction closure. Notice that the BFP location implies spreading at the Hjort trench instead of convergence. Thus, we are faced with the question: is the Minster and Jordan BFP truly the best representation of PAC-AUS relative motions? It is instructive to look at the data source for the BFP. Since there are no recognized spreading ridge or transform fault segments between the Pacific and Australia plates, all the relative motion data comes from earthquake slip vectors. Since no great subduction zone earthquakes along the Kermadec trench were used in the Minster and Jordan study, there could be a bias in the rotation pole determination. Minster and Jordan did use the slip vectors from two earthquakes in the MRC, these two occurred in 1964 and 1965 and the first-motion focal mechanisms are from BANGHAR and SYKes (1969). These two slip vectors contributed significantly to the BFP location. The magnitudes of these two earthquakes are 6.9 and 6.6 , hence they are not the most significant events in the MRC. One result of our study will be the addition of slip vectors from some of the largest earthquakes in the MRC. 
The entire catalog of MRC earthquakes is plotted in Figure 2. Notice that the seismicity is not uniformly distributed throughout the MRC. The most striking cluster is around $50^{\circ} \mathrm{S}$, with an apparent lack of seismicity both to the north and south of this cluster. The largest earthquake to have occurred since 1943, the 25 MAY 1981 event with $M_{s}=7.6$, is located in this prominent cluster. Five earthquakes with $M>7$ have occurred in the MRC since 1963. We have studied the largest of these earthquakes and have compiled the available focal mechanism information for other smaller earthquakes. Many large earthquakes occurred before 1963. Although it is difficult to study these earlier events, one aspect that can be

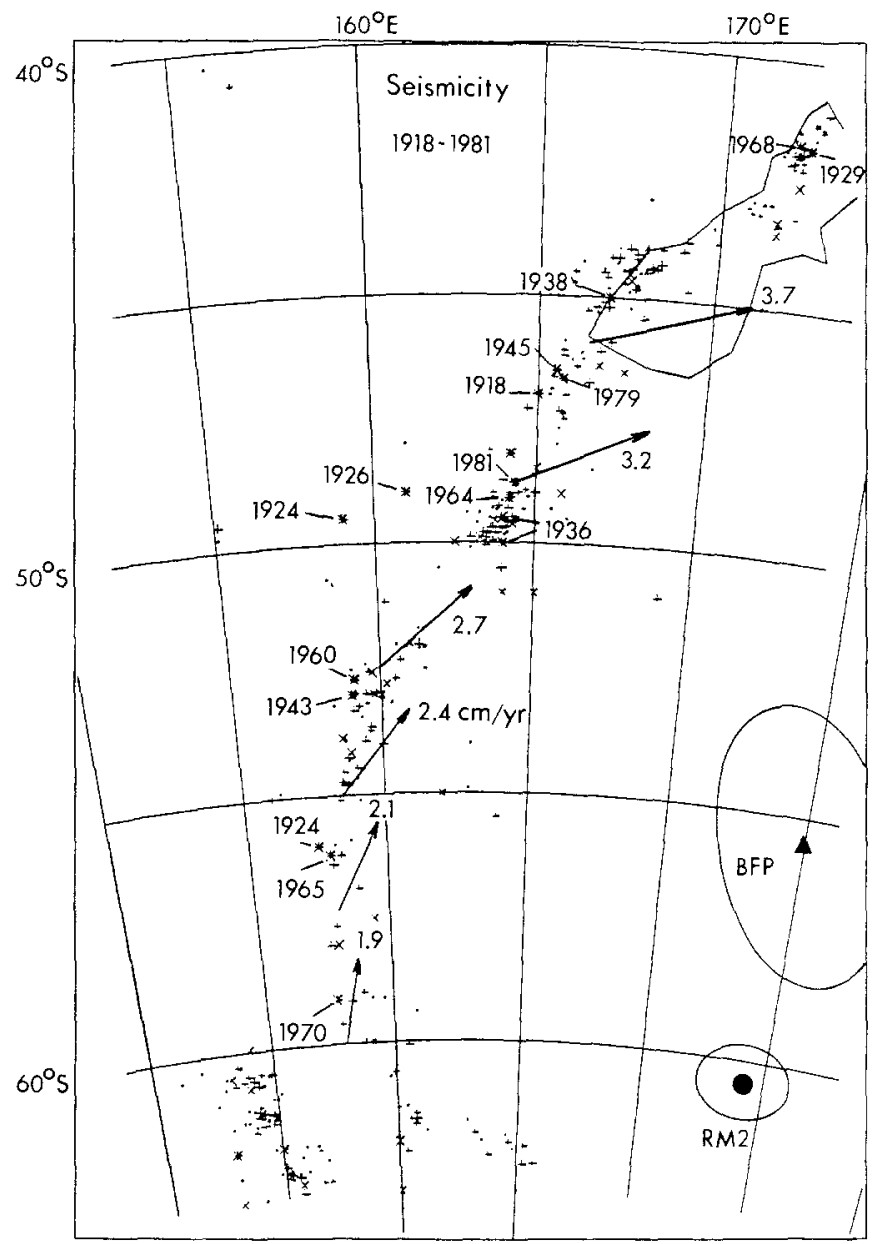

Figure 2

Macquarie Ridge complex seismicity, 1918 to 1981. All epicenters in the USCGS catalog are plotted, the magnitude threshold varies through this time period. The seismic activity is not uniform at any magnitude level. In particular, there is a concentration of events of all sizes in the region of the large 1981 earthquake from $49^{\circ} \mathrm{S}$ to $50^{\circ} \mathrm{S}$. The BFP and RM2 rotation poles are plotted. 
studied is their epicentral location. We have systematically checked the listed locations for large earthquakes that occurred between 1918 and 1963 for which the ISS catalog publishes arrival times. In addition, due to rather unique circumstances we have been able to determine focal mechanism constraints for two of these pre-1963 events. Based on this comprehensive study of large events in the MRC, we reconsider the tectonic setting. Despite the confusing seismicity, we find a consistent picture within the framework of rigid plate tectonics. We propose a model for subduction initiation based on the seismotectonics of the Puysegur trench region, and then speculate on global generalizations of the Macquarie Ridge complex tectonic environment.

\section{Large Recent (Post-1963) Earthquakes}

Focal mechanisms have been determined for only a few of the MRC events. As discussed above, only two of the smaller earthquakes were used to derive the RM2 relative plate motions. We have determined the focal mechanisms for the three largest earthquakes since 1963: the 1970 event in the Hjort trench region, and the 1979 and 1981 events in the Puysegur trench region. The 1979 and 1981 events are the two largest earthquakes in the time period from 1943 to the present. We begin with separate sections for the three earthquakes that we studied in detail, with emphasis on the large 1981 event. We then summarize the information available for all recent events.

\subsection{The Great 25 MAY 1981 Strike-slip Earthquake}

This event occurred in the seismicity cluster at the southern end of the Puysegur trench (Figure 3). The ISC hypocentral parameters for this event are: origin time, 5:25:9.4 (hr:min:s), 25 MAY 1981; epicenter, $48.55^{\circ} \mathrm{S}$ and $164.7^{\circ} \mathrm{E}$; depth, $0 \mathrm{~km}$ (constrained). With values for the surface wave magnitude ranging from 7.4 to 7.7 , this event is one of the largest earthquakes of 1981. Since it is also the largest magnitude earthquake in the MRC since 1943, any study of the mechanics of this region, and indeed of the Pacific-Australia plate interaction, must consider this event. An additional interesting aspect of this event is that the $P$ wave first-motions indicate a strike-slip focal mechanism (see Figure 4), thereby implying that this event is one of the largest strike-slip earthquakes to be well-recorded. The focal mechanisms for two smaller earthquakes in the seismicity cluster are thrust mechanisms. Therefore, it is important to ascertain whether the 1981 earthquake was in fact a strike-slip event, as opposed to a precursory strike-slip event followed by a thrust main event. To obtain the overall average focal mechanism of this event, we have used the moment tensor inversion technique described in KANAMORI and Given (1981). First we look at the aftershocks of this earthquake. 


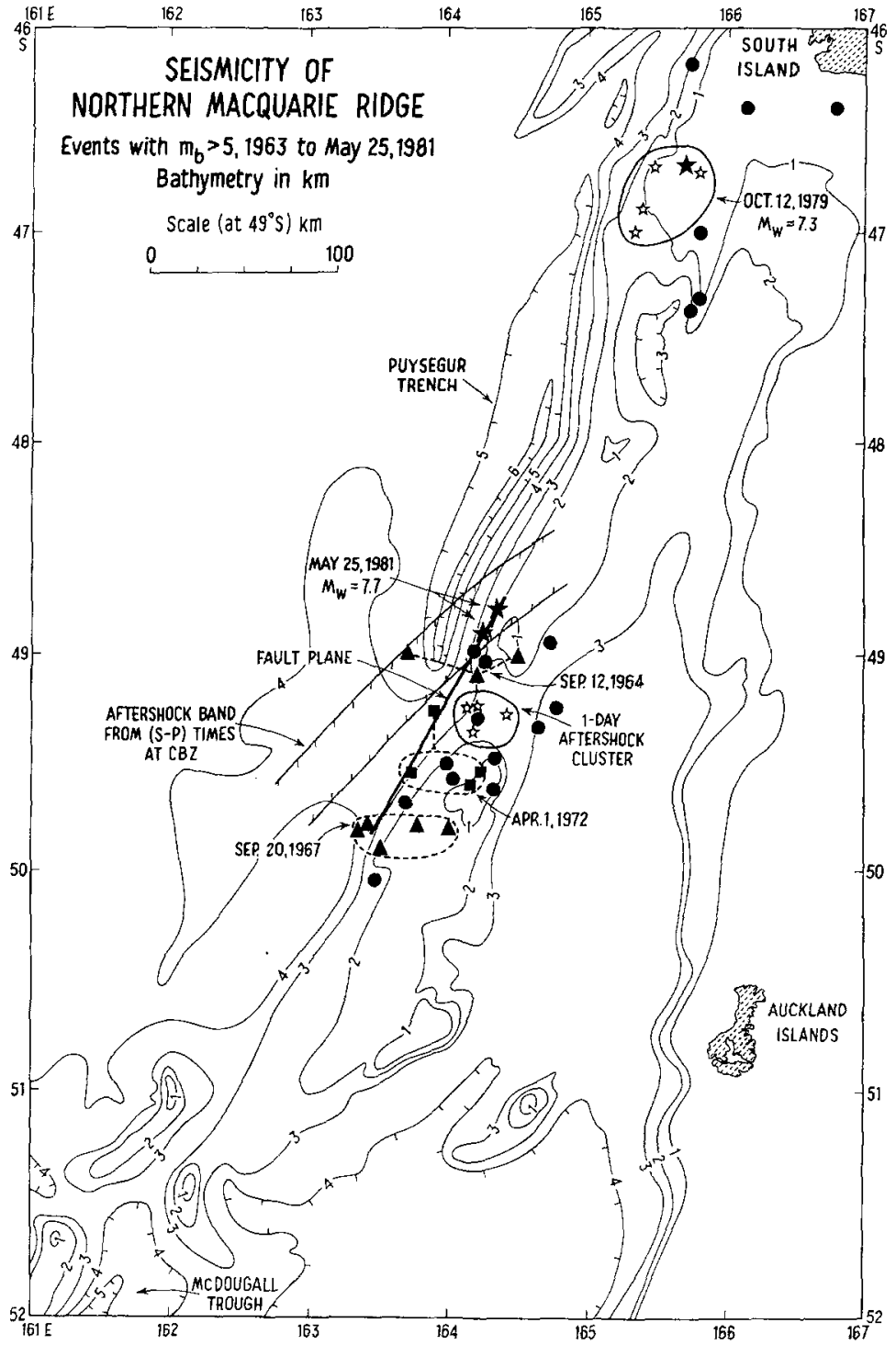

Figure 3

Detailed seismicity of the northern Macquarie Ridge, 1963 to 1981 mainshock. Epicenters and magnitudes are from the USCGS catalog. All events are larger than magnitude 5 except for three of the four events in the 1-day aftershock cluster of the 1981 event (open stars), these are the four largest aftershocks (29 or more stations reporting). All smaller aftershocks recorded at CBZ (Campbell Island) fall into the plotted band, based on relative $S-P$ times. Two possible mainshock epicenters are plotted as solid stars. The bold line through the 1981 epicenters indicates the maximum possible extent of the 1981 rupture zone. For the 1979 earthquake, the mainshock and 1-day aftershocks are plotted as the solid and open stars, respectively, with the approximate fault extent indicated by the solid line. In the 1981 region, there are several earlier sequences of mainshock/aftershocks that are linked by broken lines: 12 SEP 1964, mainshock $M=6.9$ (triangles); 20 SEP 1967, mainshock $M=6.1$ (triangles); 1 APR 1972, mainshock $M=6.3$ (squares). Focal mechanisms determined for some of these earlier events all indicate thrust faulting. Bathymetry is taken from maps published by the New Zealand D.S.I.R. Oceanographic Institute. 


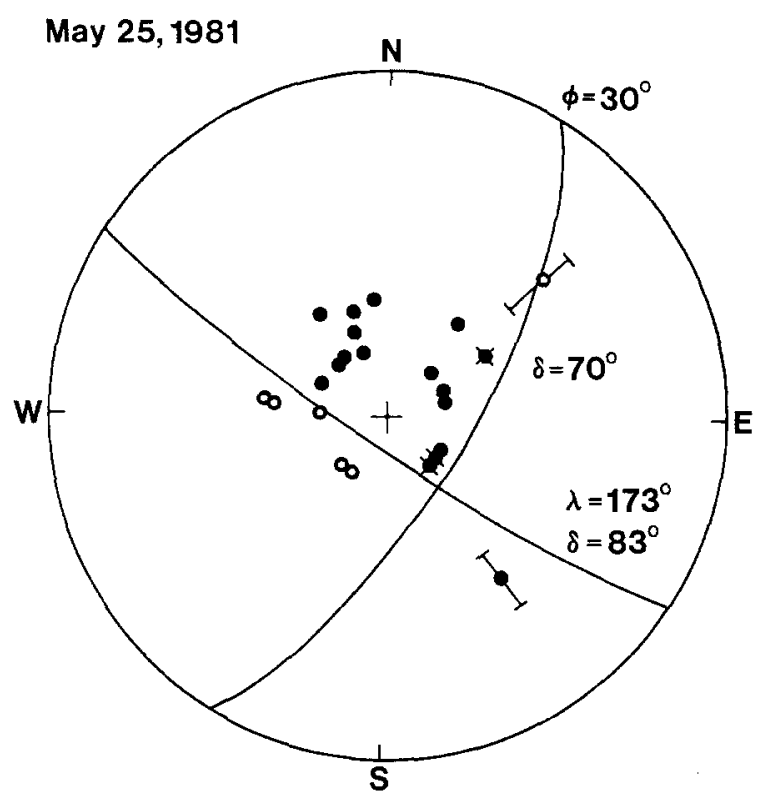

Figure 4

Preferred focal mechanism solution and WWSSN $P$ wave first motions for the 1981 event. Lower-hemisphere equal-area projection with compressional and dilatational arrivals plotted as solid and open circles, respectively. This convention is used in all subsequent focal mechanisms. Crosses indicate near-nodal readings, and error bars indicate take-off angle uncertainty associated with close stations. Parameters for the nodal planes are strike, dip, and rake $(\phi, \delta$ and $\lambda)$, and are obtained from fault plane inversion.

3.1.1. Aftershock distribution. The fault area ruptured by an earthquake is typically estimated by the one-day aftershock area. The four largest one-day aftershocks (29 or more stations reporting times) of the 1981 event are plotted in Figure 3, with magnitudes between 4.5 and 5.1 . This cluster lies about $50 \mathrm{~km}$ southwest of the epicenter and thus supports the selection of the NE-SW nodal plane as the fault plane. A rupture length of $50 \mathrm{~km}$ is much less than we would expect for a strike-slip earthquake of this magnitude. For example, the 1976 Guatemala earthquake $\left(M_{s}=7.6\right)$ had large surface displacements over a length of $250 \mathrm{~km}$ (Plafker, 1976). Even if we use all the one-day aftershocks for the 1981 event in the ISC catalog above magnitude 4 , there are no epicenters north of the mainshock nor south of $50^{\circ} \mathrm{S}$. The teleseismic one-day aftershocks for the 1981 event thus imply a rupture length of $100 \mathrm{~km}$ or less. For the 1976 Guatemala earthquake, the teleseismically recorded one-day aftershocks define a fault length of just $180 \mathrm{~km}$. However the locally recorded microaftershocks scatter over the full $250 \mathrm{~km}$ length of the fault. A similar situation is encountered for the 1972 Sitka, Alaska strike-slip earthquake $\left(M_{s}=7.6\right)$; the teleseismically located aftershocks fall into one cluster $90 \mathrm{~km}$ from the epicenter (SCHELL and RUFF, 1988) whereas the 
microaftershocks define a $180 \mathrm{~km}$ bilateral fault zone (PAGE, 1973). Given the remote oceanic location of the 1981 Macquarie Ridge event, neither a detailed aftershock study nor fault displacement mapping are possible. However, there is a seismic station on Campbell Island operated by the New Zealand D.S.I.R. Geophysics Division, and many small one-day aftershocks were recorded by this single station. The $P$ and $S$ wave picks from these 16 events were provided by Dr. Warwick Smith. The most important observation is that the $S-P$ times for all these events only range from 48.2 to 50.7 seconds, and the mainshock $S$-P time is $49.1 \mathrm{~s}$. Hence, the distance to these aftershocks varies by less than $20 \mathrm{~km}$ about the mainshock distance. Fortunately, the azimuth from Campbell Island to the mainshock is not perpendicular to the fault strike. Thus, with the assumption that the aftershocks are on the fault plane, we see that the microaftershocks cluster in the epicentral region (see Figure 3).

The aftershocks imply a fault length of only $100 \mathrm{~km}$, anomalously small for a large strike-slip event. This tentative conclusion motivates a more thorough analysis of the rupture process. Both surface waves and $P$ waves are analyzed for information on the rupture length. We use seismograms recorded by stations of the WWSSN (in operation since 1963), GDSN (in operation since 1980), IDA (in operation since 1977), and Caltech.

3.1.2. Rayleigh and Love waves. GDSN stations are azimuthally well distributed about the 1981 earthquake (Figure 5). Figures 6 and 7 show three-component filtered traces from the GDSN digital recordings. These filtered traces emphasize the multiple orbit surface waves around a period of $250 \mathrm{~s}$, the "mantle waves". The long-period spectral amplitude and phase from these high quality digital records can be inverted to obtain the seismic moment and faulting geometry. The procedure is fully documented in KANAMORI and Given (1981), and has been successfully applied to many earthquakes over a large magnitude range. Due to the shallow depth of this earthquake (less than twenty kilometers), the vertical dip-slip component is unresolved, as discussed in KANAMORI and GIVEN (1981), and some type of constrained moment tensor inversion is necessary. We shall use two different modes of the constrained moment tensor inversion: (1) linear inversion for a moment tensor constrained to have no isotropic nor vertical dip-slip components, (2) nonlinear fault inversion where we constrain one nodal plane. For the linear inversion, the moment tensor is resolved into two double couples. If we assume that the larger double couple represents the actual faulting, then the fractional size of the second double couple is a measure of the reliability of the solution. The second double couple is relatively small in all cases for the 1981 event; this supports the notion that this earthquake has a single dominant focal mechanism. We have inverted various subsets of our data to test the reliability of the results. The constrained moment tensor inversion always yields a strike-slip mechanism, with right-lateral motion along the NE-SW plane. Figure 8 summarizes the solutions for 


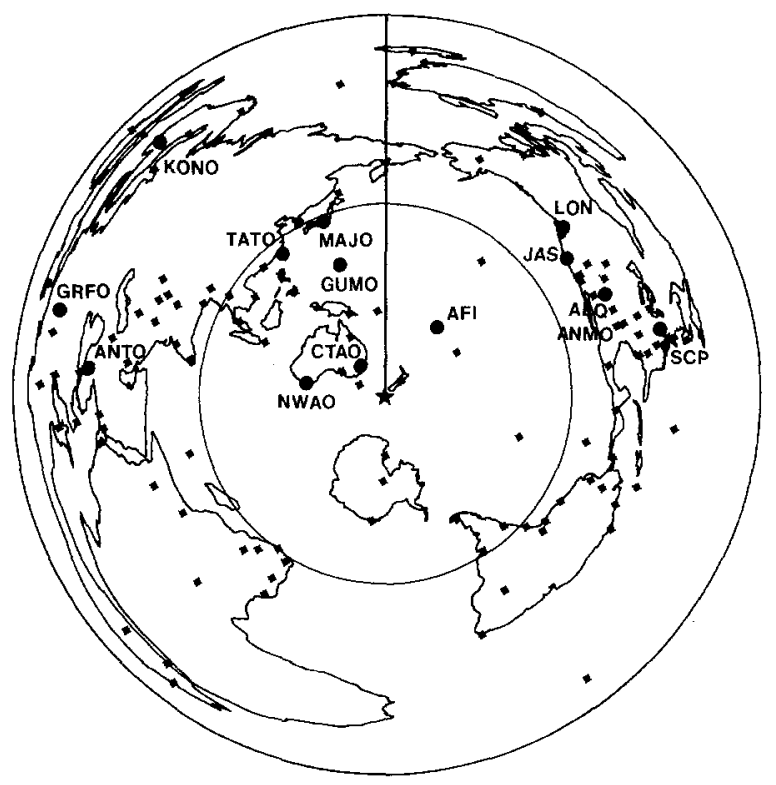

Figure 5

Azimuthal equidistant world map centered on the 1981 epicenter (star). The solid straight line passes through the North Pole. The GDSN stations used in this study are plotted as large dots, the other symbols show WWSSN station locations. Although the GDSN stations are in the two northern quadrants, multiple orbit surface waves provide excellent azimuthal coverage.

different combinations of data. Note that the strike of the NE plane is in excellent agreement with the $P$ wave first-motions, though the first-motions clearly indicate a dip of $\approx 70^{\circ}$ rather than $90^{\circ}$ (see Figure 9). Figure 10 shows the spectral amplitude and phase for Rayleigh and Love waves with the predicted values from the constrained moment tensor inversion. Inclusion of phase data in the inversion seems to result in a lower moment estimate. To improve the solution, we can constrain one nodal plane and invert for the slip vector angle and the seismic moment. We constrain the NE trending plane to have a strike of $30^{\circ}$ (clockwise from north), and vary the dip as shown in Figure 9. For the various data subsets, we always obtain right lateral strike-slip with a small oblique component. Our best estimate for the seismic moment with a point source assumption is $4.5 \times 10^{27} \mathrm{dyn} \mathrm{cm}$, and the best fault geometry is shown in Figure 4. The excellent correspondence between the surface wave focal mechanism and the $P$ wave first motions shows that the faulting geometry remained constant for the duration of the earthquake.

DZIEWONSKI and WOODHOUSE (1983) also inverted GDSN data to obtain a moment tensor solution for the 1981 event. The major double couple of their solution has the following fault parameters: a fault strike of $31^{\circ} \mathrm{E}$, fault dip of $66^{\circ}$, and a rake of $186^{\circ}$. The seismic moment is $2.7 \times 10^{27} \mathrm{dyn} \mathrm{cm}$, and the size of the 


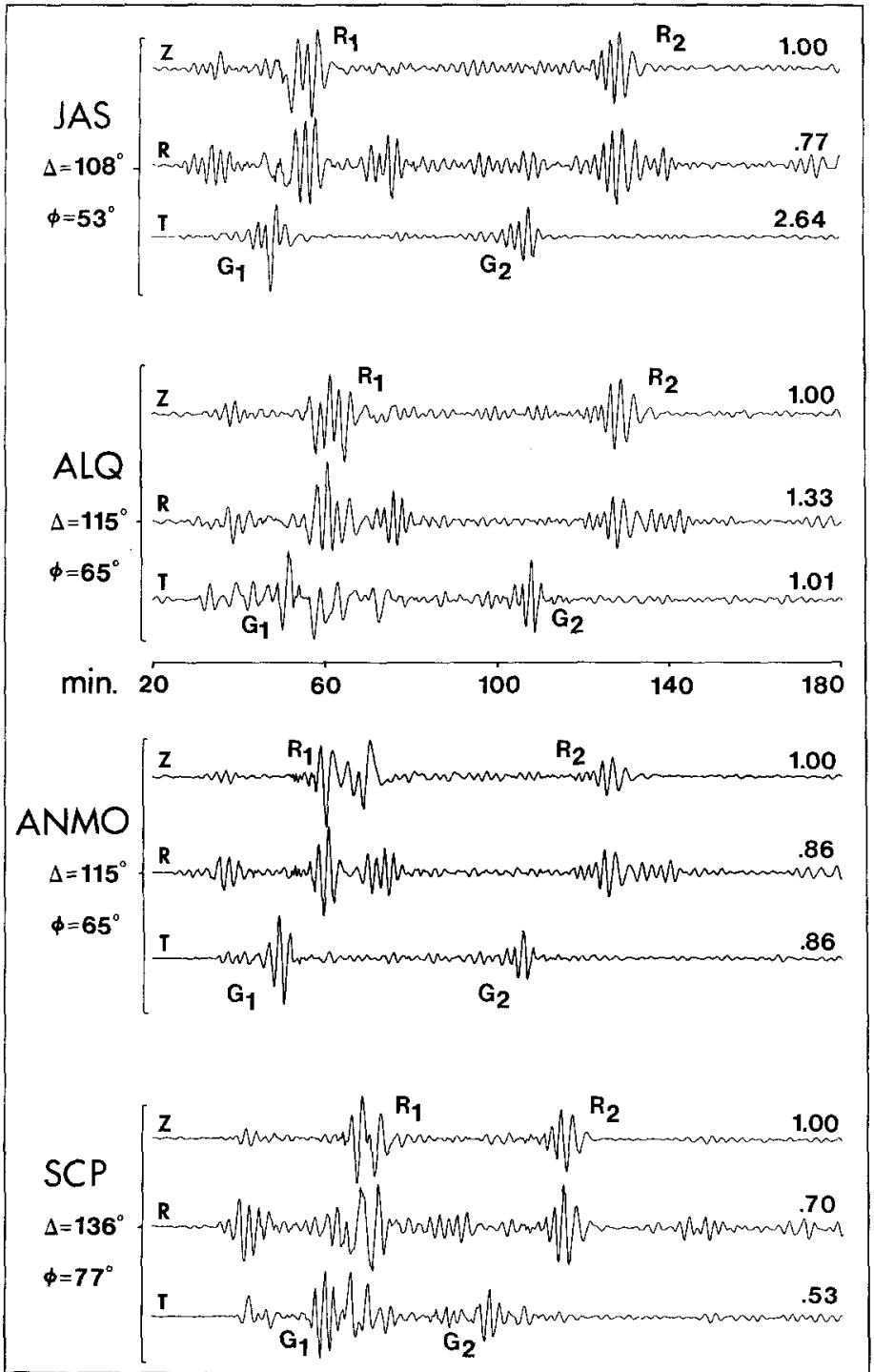

Figure 6

Filtered traces from GDSN stations, station codes are at left with distances and azimuths. Nearly three hours of three-component long period channels are filtered to enhance the "mantle wave" periods. The horizontal components are rotated into radial and transverse components, thereby isolating the Rayleigh waves on the $Z$ and $R$ traces and the Love waves on the $T$ trace. Multiple orbit Rayleigh and Love waves are well recorded. Time scale refers to minutes after origin time. The numbers for each trace give the maximum peak-to-trough amplitude relative to the $Z$ trace for each station, amplitudes are arbitrarily scaled between stations. 


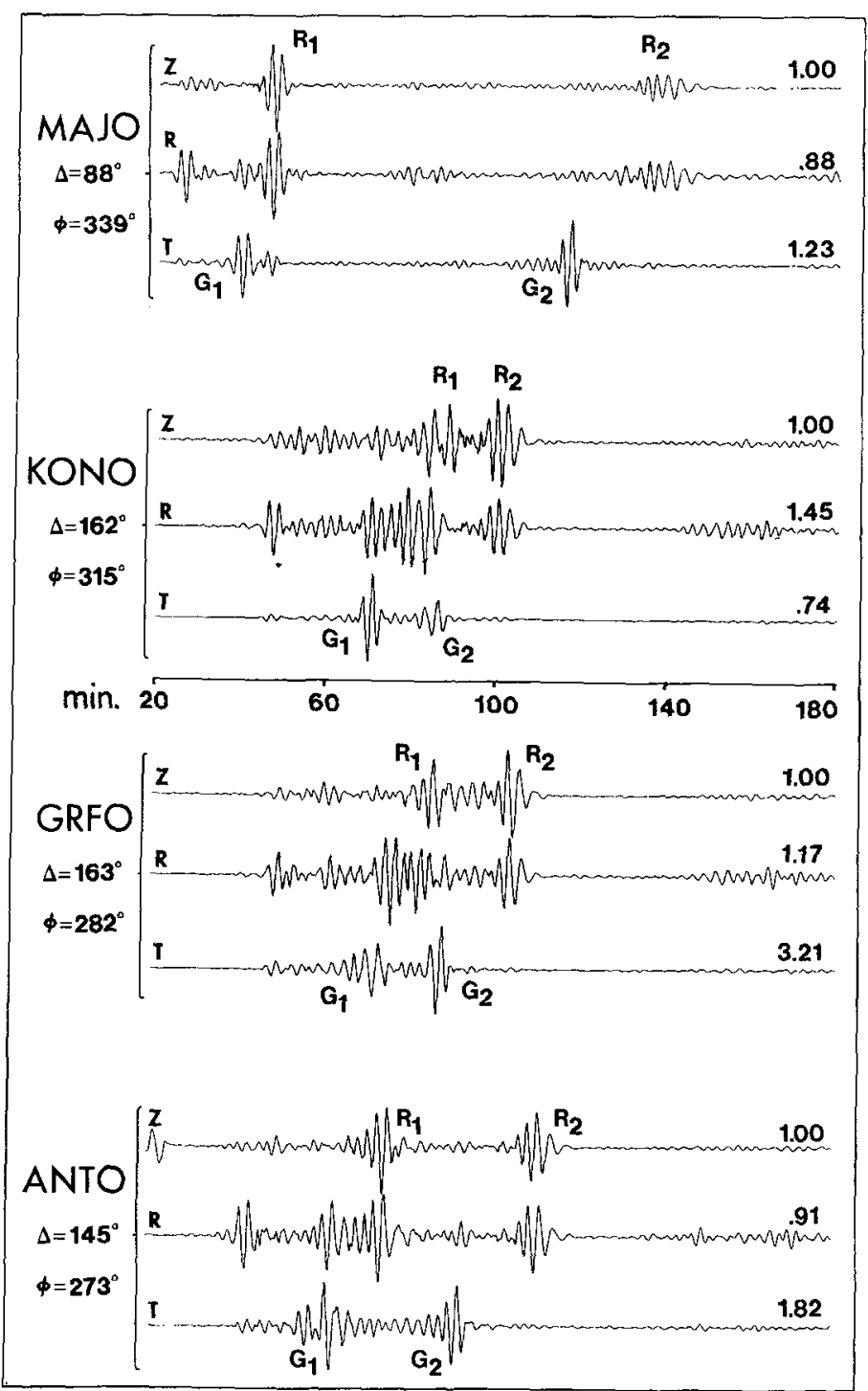

Figure 7

Same as Figure 6.

second double couple is about $1 / 10$ the size of the major double couple. The fault geometry of the Harvard CMT solution is very similar to our solution, but their seismic moment is about half of our value. There are several significant differences between the Harvard CMT (DzIEwONSKI et al., 1981) and the Kanamori and Given techniques. The Harvard inversion includes shorter period information, and inverts for the spatial and temporal centroid of the moment density function. The 


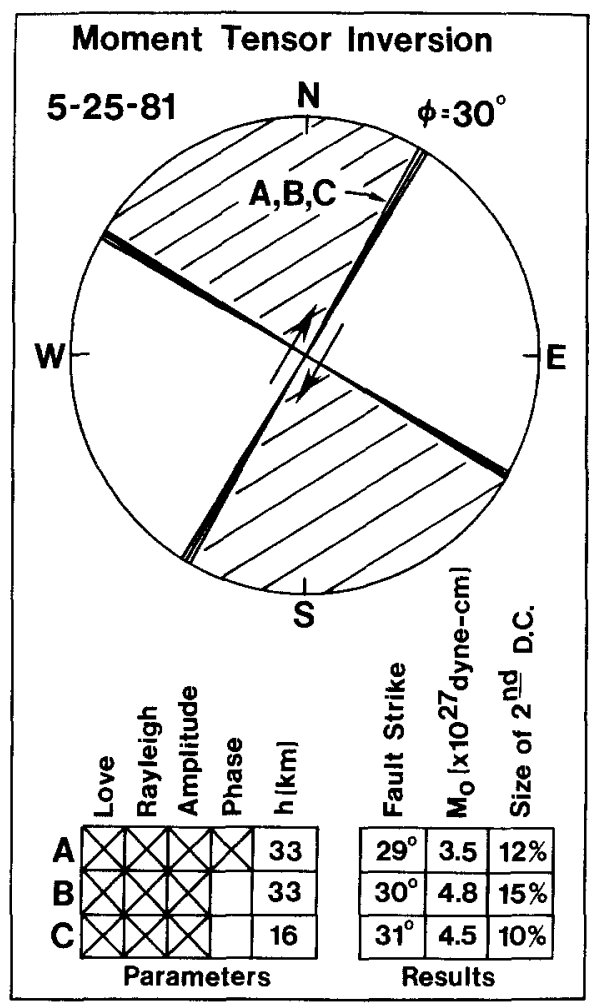

Figure 8

Summary of moment tensor inversion for three different cases (A, B, and C). The major double couple is a strike-slip focal mechanism for all cases. Box on left shows the data set and assumed depth, while the box on right shows the resultant fault strike, seismic moment, and relative size of the second double couple. Right lateral strike-slip along a fault strike of $\mathrm{N} 30^{\circ} \mathrm{E}$ is clearly a consistent result.

CMT inversion can potentially yield more information about the earthquake, but it is also possible that lack of coherence at the shorter periods might produce a smaller moment estimate than the Kanamori and Given technique.

To test the robustness of our results, we have used the Harvard CMT spatial and temporal centroid values and recomputed the solution with the Kanamori and Given technique. We have also added several more Rayleigh wave phases recorded by IDA stations, and performed the inversion at periods ranging from $150 \mathrm{~s}$ to more than $300 \mathrm{~s}$, with and without finite faulting; we find the faulting geometry to be extremely stable. Our overall best estimate for the seismic moment that matches both Rayleigh and Love wave lobe amplitudes for finite faulting is $5 \times 10^{27} \mathrm{dyn} \mathrm{cm}$. The moment magnitude (KANAMORI, 1977) for the 1981 event is then $M_{W}=7.7$. We conclude that both the faulting geometry and seismic moment are well resolved. 


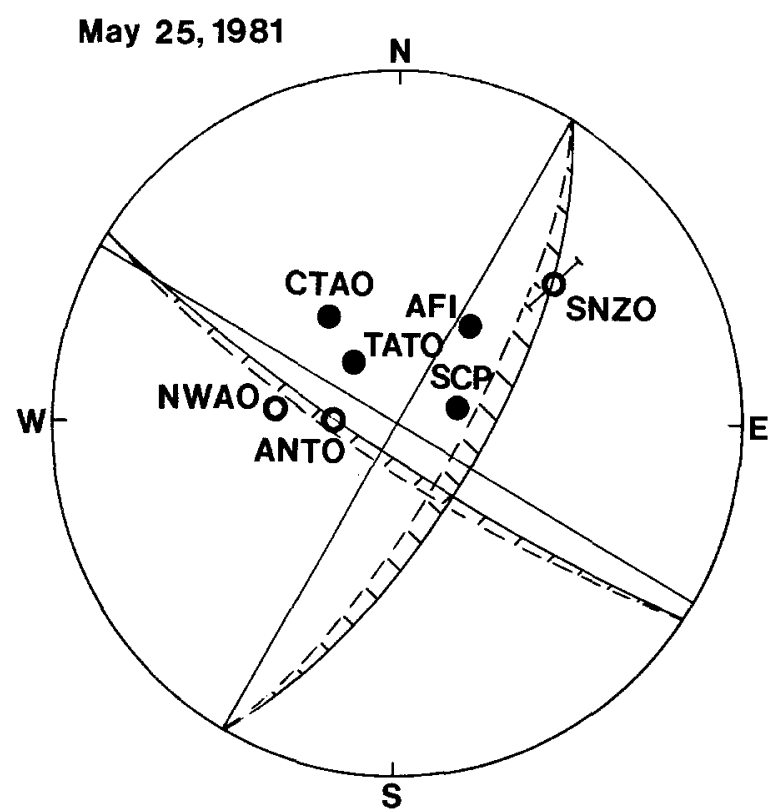

Figure 9

Summary of fault plane inversion results. The pure strike-slip mechanism with a $\mathrm{N} 30^{\circ} \mathrm{E}$ strike is shown. $P$ wave first motions from GDSN stations are plotted. The dip of the $N 30^{\circ} \mathrm{E}$ nodal plane is varied within the hachered region.

3.1.3. Surface wave directivity. We looked for evidence of fault finiteness in the long-period surface waves. Unilateral rupture propagation with uniform moment release produces a consistent azimuthal asymmetry in the long-period surface wave amplitudes (BEN-MENAHEM, 1961). The moment tensor inversion results presented in Figure 10 assume a point source; the directivity effect consists of a systematic azimuthal variation in the amplitude residuals. We can obtain useful constraints on the fault length by using the amplitudes from several different periods. It is desirable to work with the ratio of spectral amplitudes between even and odd order arrivals at a single station to cancel common effects. It is also possible to use variations in the phase, or in group delays, to obtain the temporal and spatial information (see KANAMORI and Given, 1981). The Harvard CMT technique routinely uses this type of information.

The strongest directivity effects for unilateral rupture are observed at azimuths along the fault strike. Fortunately, lobes of the Love wave radiation pattern coincide with fault strike for strike-slip earthquakes. For the 1981 event, there are three GDSN stations in the western U.S.A. along the fault strike azimuth. Since the G1 phase was not reliably recorded by all stations, we perform the analysis using 


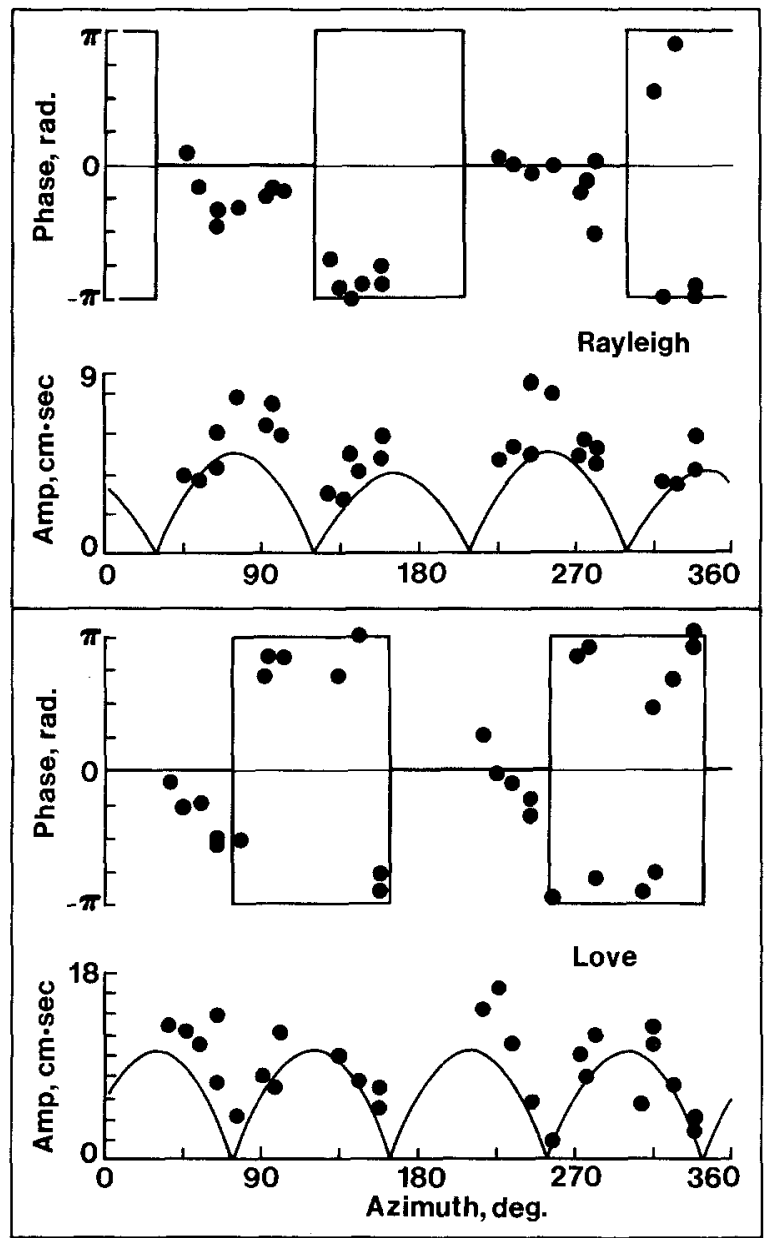

Figure 10

Detailed moment tensor results for case $\mathrm{A}$ of Figure 8 . The inversion uses both Rayleigh and Love wave spectral amplitudes and phases at a period of $256 \mathrm{~s}$. All individual data points are plotted as solid dots, with the predicted radiation pattern and phase curves also plotted. A source phase shift of $45 \mathrm{~s}$ has been applied to the observed phase.

G2 and G3. Figure 11 shows the observed spectral ratios for the three stations. There is little coherence between the curves for each station, the only reliable feature is the overall range of the different curves, i.e., the data band. Figure 11 also shows theoretical curves representing various rupture modes and the data band. The curve for $100 \mathrm{~km}$ fault length falls in the middle of the data band. The curves for a fault length of $150 \mathrm{~km}$ or longer clearly deviate from the data band. We conclude that a rupture mode of unilateral propagation to the southwest for about $100 \mathrm{~km}$ is consistent with the surface wave data. 


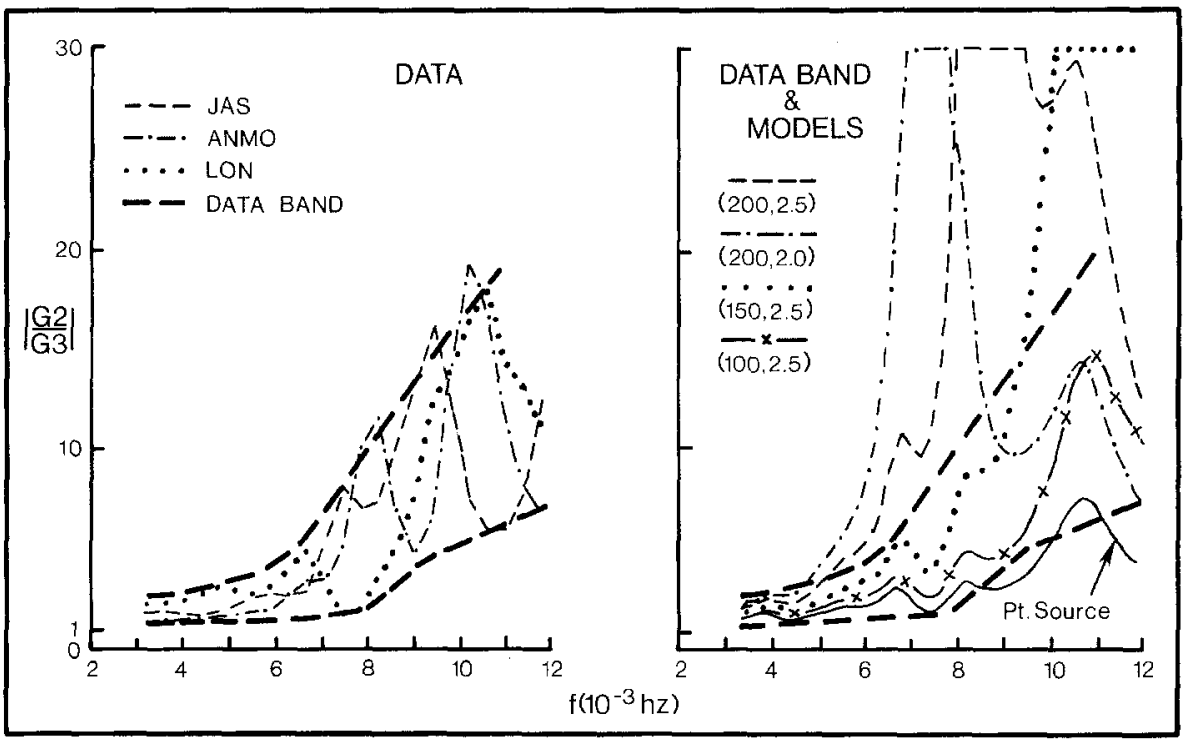

Figure 11

Test for Love wave directivity. The azimuth to western U.S.A. stations coincides with fault strike and Love wave radiation maximum. Spectral ratios between G2 and G3 waves recorded by GDSN stations are plotted in the lefthand graph. There is scatter between the results from individual stations, but together they define a data band. A comparison of this data band with curves calculated for different faulting parameters is shown in the righthand graph. The numbers in parentheses in the legend are the fault length and rupture velocity, in $\mathrm{km}$ and $\mathrm{km} / \mathrm{s}$ respectively. The comparison implies a short fault length for the 1981 event.

3.1.4. $P$ waves and the rupture process. Source time functions deconvolved from teleseismic $P$ waves display the basic temporal history of moment release. Figure 12 shows the source time functions deconvolved from $P$ waves recorded by GDSN stations and the 30-90 instrument at Pasadena, CA U.S.A. (see RUFF and KANAMORI, 1983, for discussion of the deconvolution technique). The primary feature of both the observed seismograms and the source time functions is the distinct double-event character. The second event follows rupture initiation by about $30 \mathrm{~s}$. This second event seems more consistent from station to station than the first event, which splits into two subevents at some stations. The sharp rise in moment release at the onset of the second event produces a distinct break in the WWSSN long-period $P$ waves (see Figure 13). The WWSSN $P$ wave records provide nearly complete azimuthal coverage about the epicenter. The good azimuthal coverage and the distinct break of the second event onset allow a directivity analysis to determine the location of the second event onset relative to the epicenter. This procedure is analogous to relative earthquake location (see BECK and RUFF, 1985, for other applications). The implicit assumptions for this procedure are ideally suited for strike-slip earthquakes, where we can regard the fault surface as a thin 


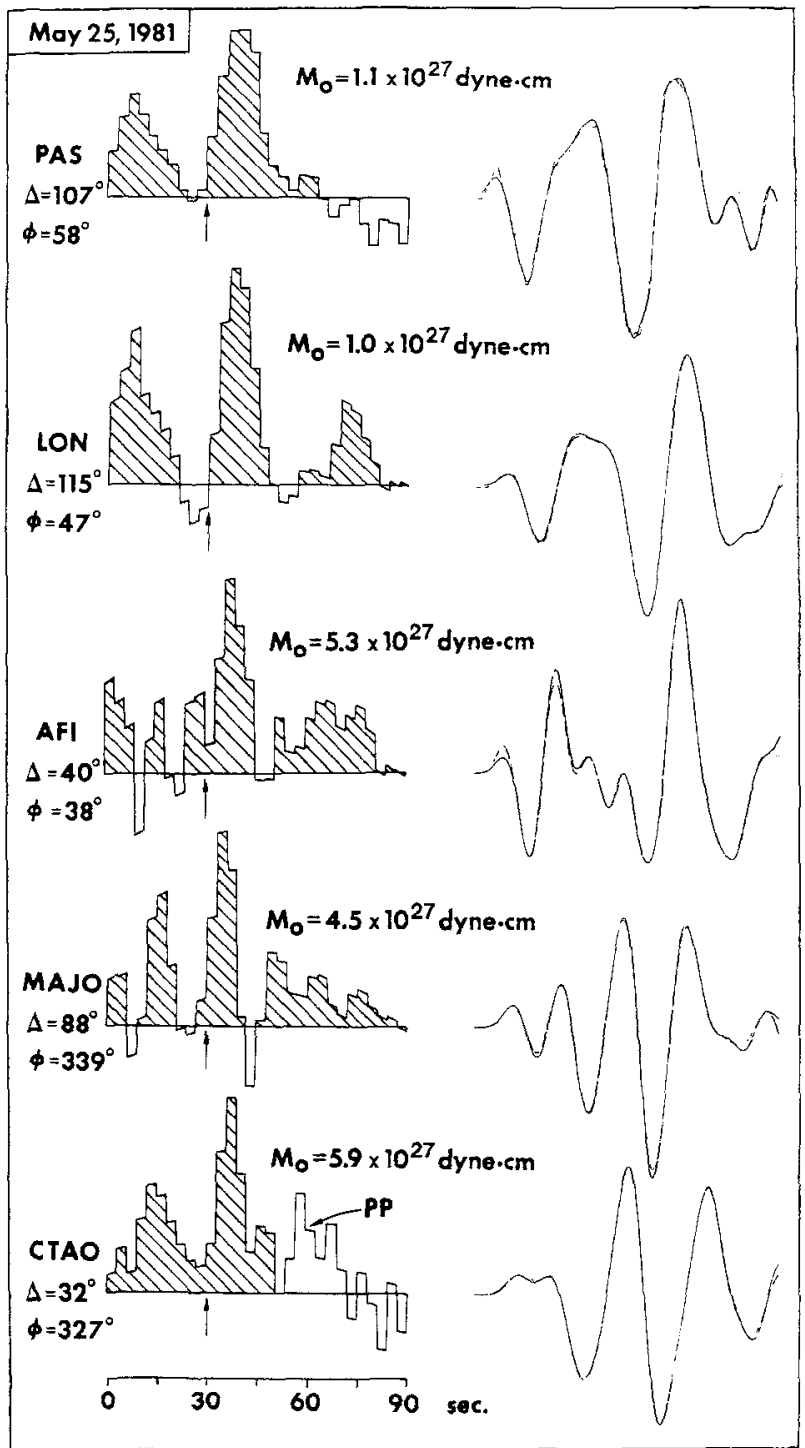

Figure 12

Source time functions and $P$ waves for the 1981 event. Station code, distance, and event-station azimuth are listed for each station. The deconvolved source function is at left, while the observed and synthetic $P$ wave seismograms are plotted together as solid and dashed traces, respectively (same convention in all subsequent source time function plots). The seismic moment for each time function is also shown. The arrows point to the second event onset at $30 \mathrm{~s}$, and the $P P$ arrival at CTAO is noted. The strong second event is easily seen in both the $P$ wave seismograms and source time functions. 


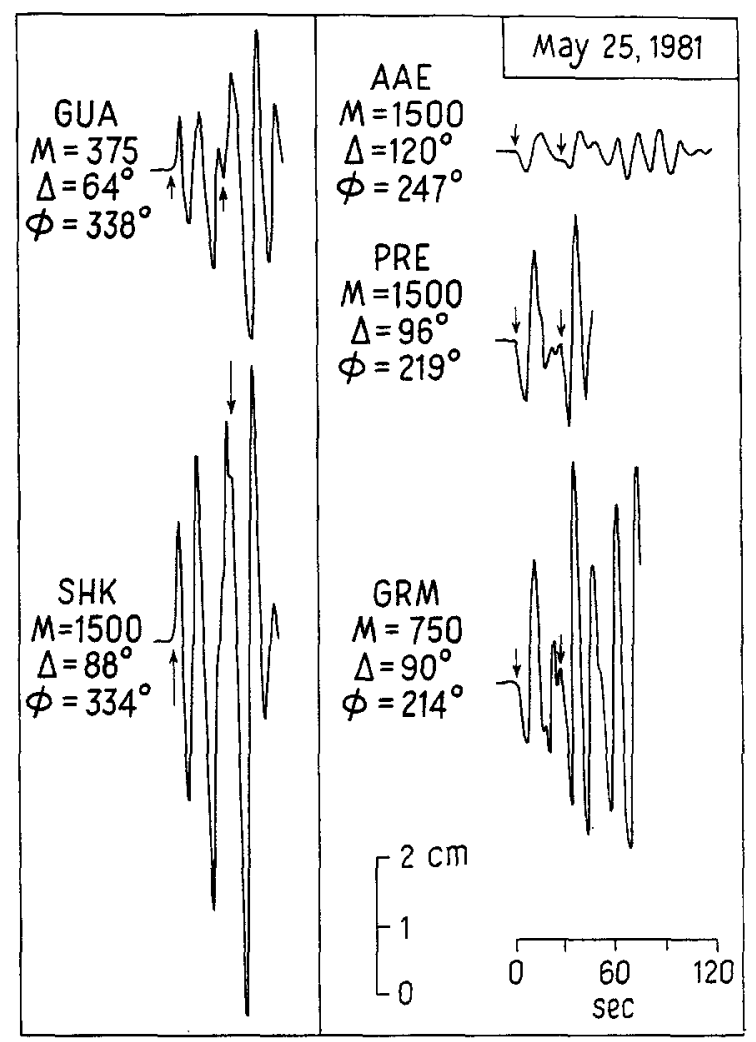

Figure 13

WWSSN long period vertical component $P$ waves for the 25 MAY 1981 earthquake. Station code, epicentral distance, and azimuth are listed for each $P$ wave. Amplitude scale refers to trace amplitude on the original records at listed magnifications. The arrows show the initial $P$ wave arrival and the second event onset.

horizontal strip (see RUFF, 1983, for derivation of the ribbon fault model). The time difference between the first and second event onsets shows an azimuthal variation of only a few seconds. Close examination reveals that time differences at southern azimuths are perhaps $4 \mathrm{~s}$ less than those from northern azimuths. This implies that the second event initiated at about $50 \mathrm{~km} \mathrm{SW}$ of the epicenter.

Short period records potentially offer better time resolution of source pulses. However, we must convince ourselves that a short-period break reflects a significant event in the long-period moment release, and that we can associate the same breaks between different stations. For the 1981 event, we are lucky in both respects. Figure 14 shows two WWSSN short-period records at NE and SW azimuths. There is a consistent break that seems to correspond to the second event initiation. From these two short-period records, we can see a $4.5 \mathrm{~s}$ directivity time shift. This time difference, combined with a $P$ wave slowness appropriate for these stations, yields 


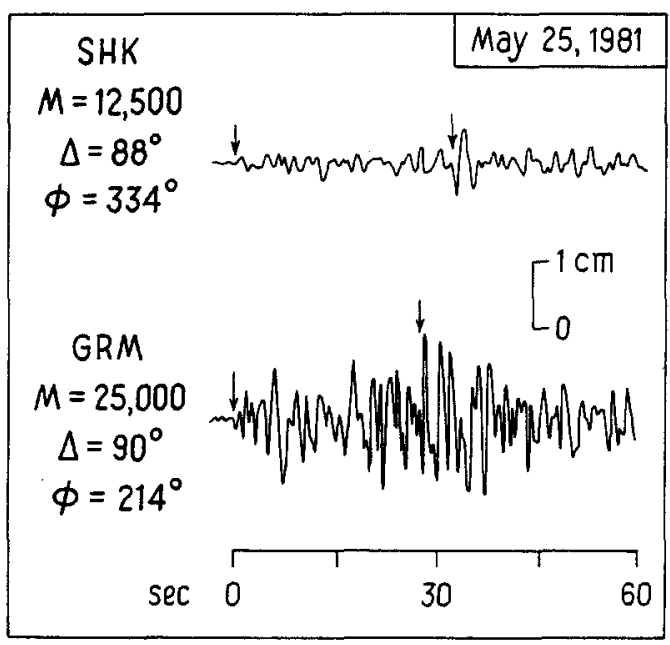

Figure 14

WWSSN short period vertical component $P$ waves for the 25 May 1981 earthquake. Station code, epicentral distance, and azimuth are listed for both seismograms. Amplitude scale refers to original trace amplitude for the listed magnifications. The first arrow shows the initial $P$ wave arrival. The second arrow shows a distinct break that we associate with the second event onset in the long period records.

a spatial separation of $\approx 50 \mathrm{~km}$ to the southwest. Thus the large second event initiates about $50 \mathrm{~km} \mathrm{SW}$ of the epicenter in the vicinity of the aftershock cluster (see Figure 3). Note that the apparent rupture velocity between the epicenter and the second event onset is $1.7 \mathrm{~km} / \mathrm{s}$. The duration of the second event is about $16 \mathrm{~s}$; even if we assumed a much faster rupture velocity of $4 \mathrm{~km} / \mathrm{s}$ to the south, the total fault length is no more than $100 \mathrm{~km}$.

Nearly all of the moment release occurs in the two events found in the $P$ waves. Although there might be additional moment release after the second event, it is only a small fraction of the total. The seismic moment in the deconvolved time functions from nondiffracted stations scatters about the surface wave moment estimate. Hence, there is no evidence for an additional long-period component of moment release in the time functions (for an example of this behavior, see BECK and RUFF, 1984). Therefore, we conclude that the rupture process of the 1981 event is characterized by unilateral propagation to the southwest with most of the moment released in two events with a spatial extent of $100 \mathrm{~km}$ or less. There seems to be a concentration of moment release at the second event onset, $50 \mathrm{~km} \mathrm{SW}$ of the epicenter, that coincides with the cluster of the largest aftershocks.

The source time functions in Figure 12 are deconvolved for a point source at $10 \mathrm{~km}$ depth. This implies a fault width of $20 \mathrm{~km}$ if the moment release is uniformly distributed down from the ocean bottom. It is in fact quite difficult to resolve the depth distribution of large shallow events. The long-period surface waves clearly 
cannot resolve the difference between, for example, 16 and $33 \mathrm{~km}$ depth. The $P$ waves offer better resolution than the long-period surface waves, but there are difficulties. CHRISTENSEN and RUFF (1985) demonstrated both theoretically and empirically a characteristic behavior of source time functions that are deconvolved at the incorrect depth. Namely, the source time function becomes more "complicated" and develops extraneous multiple pulses when the assumed depth is greater than the true depth. Thus, we can deconvolve source functions for a range of depth assumptions, and the best depth estimate corresponds to the simplest source function as determined by visual inspection or some statistical measure. Figure 15 shows the focal depth test for the 1981 event for station MSO. A depth below $20 \mathrm{~km}$

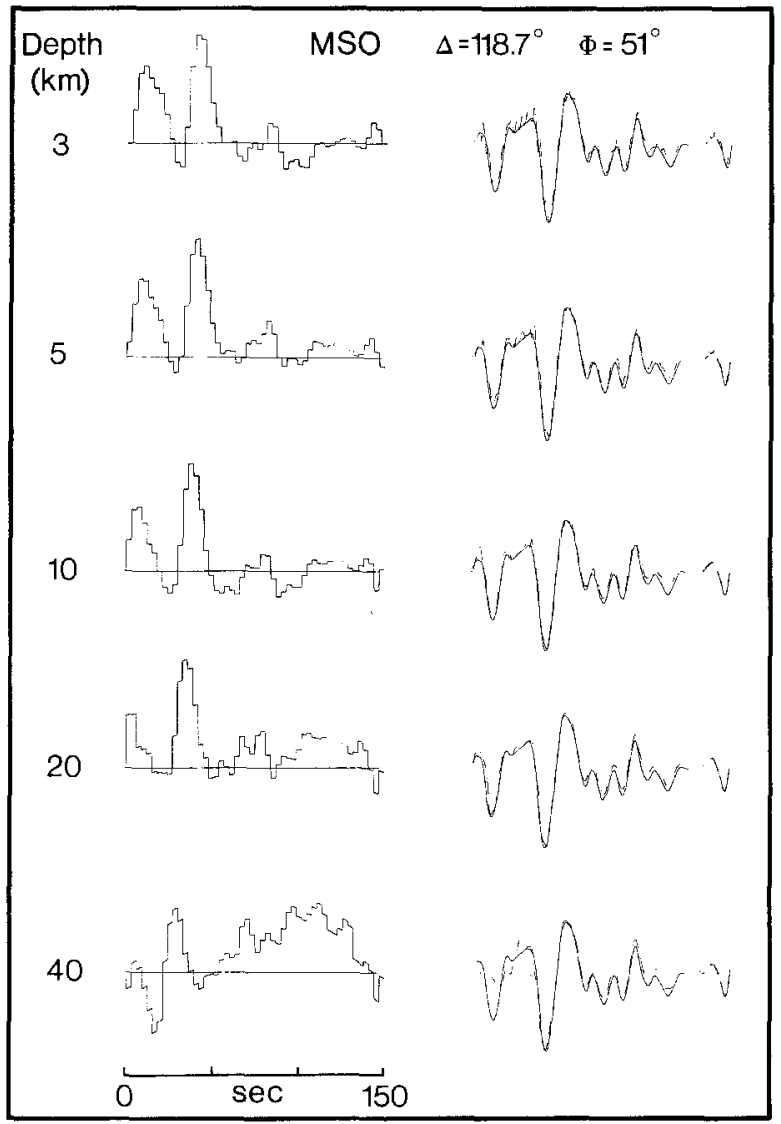

Figure 15

Focal depth test for the 25 MAY 1981 earthquake. The $P$ wave recorded at MSO is deconvolved for different depth assumptions, ranging from 3 to $40 \mathrm{~km}$. Plotting convention is the same as in Figure 12. Water layer multiple bounces with a $2 \mathrm{~km}$ ocean depth are included in the Green's function. The listed depth refers to distance below the ocean-earth interface, and a $P$ wave velocity of $6.6 \mathrm{~km} / \mathrm{s}$ is assumed.

The simplicity criterion for depth selection indicates a best point source depth of 5 to $10 \mathrm{~km}$. 
is not acceptable. Although it is difficult to choose between the 5 to $10 \mathrm{~km}$ cases, we found that a point source depth of $10 \mathrm{~km}$ produces adequate results for all seismograms. Thus, the fault width is $20 \mathrm{~km}$ or less.

3.1.5. $P$ waves: unexplained features. We end our $P$ wave analysis by pointing out that there are still some unexplained aspects of the rupture process that are exhibited in the $P$ waves. We stated above that there is no significant moment release, in terms of the total seismic moment, after the second event. Indeed, there are no large features in the source functions beyond the second event at stations in the NE quadrant, e.g., MSO. However, this is not true at other azimuths. Figure 16 shows $P$ waves recorded by long period WWSSN instruments. Unlike the vertical component $P$ waves in Figure 13 that eventually go off-scale, these $P$ waves are on-scale for three or more minutes. $P$ waves at the NW and SW azimuths show additional pulses after the second main event. Several seismograms display a nearly constant amplitude level for almost three minutes. These quasi-harmonic pulses are quite coherent between stations in any one azimuthal sector, but clearly change as a function of azimuth. Nodal seismograms will typically display this behavior, but not all of these stations are nodal. Another possibility is that these oscillations are multiple reflections within the ocean layer. These water bounces usually do not

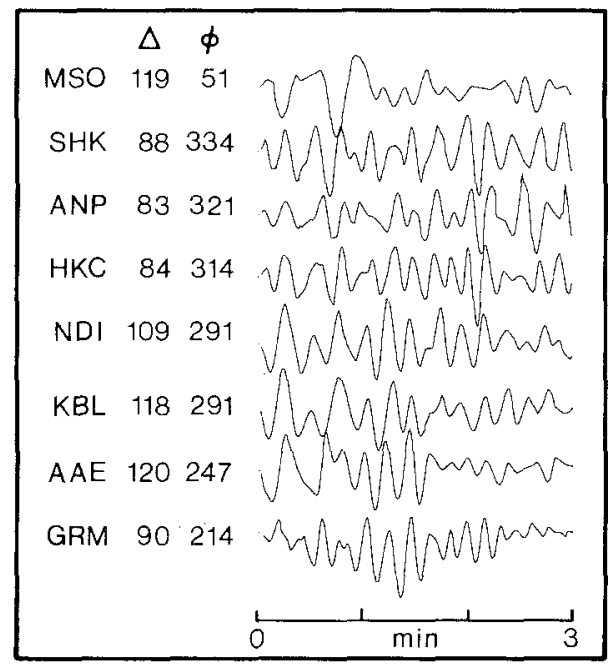

Figure 16

$P$ waves of the 25 MAY 1981 earthquake recorded by WWSSN long period instruments. Station code, distance, and azimuth (in degrees) are listed in front of the traces. The seismograms are ordered by azimuth, counter-clockwise from NE to SW. Due to off-scale $Z$ components, the $N$ component records are used for stations SHK, ANP, HKC, and GRM (there is long period drift in the GRM record). Amplitudes are scaled to the same range for each trace. This comparison illustrates the azimuthal dependence of the quasi-harmonic oscillations after the second event, yet the oscillations are coherent in any one azimuthal sector. 
affect long period records unless the water depth is quite deep and the focal mechanism is favorable, and even then a very shallow focal depth is required (see WARD, 1979; BECK and RUFF, 1987). At first glance, water bounces seem to present an attractive mechanism to explain the azimuthal variation: waves to the NE stations might see a water depth of less than $2 \mathrm{~km}$, while waves to the NW and SW might bounce in the deeper water of the Puysegur trench. However, a preliminary quantitative exploration of this hypothesis does not satisfactorily explain the differences between the seismograms. A comparison of the $P$ wave Green's functions indicates that the NW and SW stations might be more sensitive than the NE stations to small changes in the focal mechanism. While we are reasonably confident of the main conclusions regarding the 1981 event, i.e., seismic moment, focal mechanism, fault dimension, and double event character, there are unexplained complications in the $P$ waves after the second main event. Earthquakes do not easily yield all their secrets.

3.1.6. Seismic displacement and static stress drop. We have determined the seismic moment and fault dimension for the 1981 event. Other seismological quantities can be inferred from these fundamental parameters. From the basic definition of seismic moment $\left(M_{0}\right)$, the seismic displacement averaged over fault area is given by: $D=M_{0} /(\mu L W)$, where the fault area is $A=L W$, with $L$ and $W$ the fault length and width respectively, and $\mu$ is the source region shear modulus. With a seismic moment of $5 \times 10^{27} \mathrm{dyn} \mathrm{cm}$, a shear modulus of $3 \times 10^{11} \mathrm{dyn} \mathrm{cm}^{-2}$, and a fault length of $100 \mathrm{~km}$, the average displacement is $D=\left(1.7 \times 10^{4}\right) W^{-1} \mathrm{~m} \mathrm{~km}$. While it is difficult to precisely determine the fault width, our satisfactory $P$ wave modeling with a point source depth of $10 \mathrm{~km}$ implies that the fault width is $20 \mathrm{~km}$ or less. Substituting $20 \mathrm{~km}$ into the above formula, $D=8.5 \mathrm{~m}$, and any decrease in $W$ or $L$ increases $D$. To calculate the repeat time of a 1981-type earthquake for this minimum estimate for $D$, we use a strike-slip velocity component of about $2 \mathrm{~cm} / \mathrm{yr}$ and the simplest assumption for the recurrence interval of a 1981-type event: each event ruptures the same segment with the same displacement. With these assumptions, the recurrence interval is about 400 years. There is no historical record available to check this value, so it must be regarded as an order of magnitude estimate.

The standard formula for the static stress drop of an infinitely long strike-slip earthquake that ruptures from the surface to a depth $W$ is: $\Delta \sigma=(2 / \pi) \mu(D / W)$. Of course, this formula is based on physically incorrect assumptions, e.g., the displacement is uniform and drops to zero at the fault edge, but it provides a useful basis for comparing different earthquakes. With the above parameter specifications, we obtain a stress drop of about 80 bars for the 1981 earthquake. This value is at the upper bound of observed stress drops for interplate strike-slip earthquakes (see KANAMORI and ANDERson, 1975; PURCARU and BerCKHEMER, 1982). Note that if the fault width is $10 \mathrm{~km}$ rather than $20 \mathrm{~km}$, the stress drop increases by a factor 
of four to 320 bars. For comparison, the stress drop for the 1975 North Atlantic "intraplate" strike-slip earthquake is 140 bars (LYNNES and RUFF, 1985), the average stress drop for the 1972 Sitka strike-slip earthquake is 100 bars for a $10 \mathrm{~km}$ fault width (SCHELL and RUFF, 1988), while the average stress drop for the 1976 Guatemala earthquake is only 30 bars (KANAMORI and STEWART, 1978). Thus, it appears that the 1981 Macquarie Ridge event has a higher average stress drop than other large interplate strike-slip events. We return to this aspect later in our seismotectonic discussion.

\subsection{The 12 OCT 1979 Puysegur Trench Earthquake}

The 1979 event (ISC parameters: origin time, 10:25:23.1, hypocenter, $46.54^{\circ} \mathrm{S}$ $165.9^{\circ} \mathrm{E} h=33 \mathrm{~km}, M_{s}=7.4$ ) is the second largest MRC earthquake since 1963. This event is located at the northern edge of the Puysegur trench where the continental shelf of South Island is encountered. Events in 1918 and 1945 of unknown mechanism occurred in this same region. The $P$ wave first motion data are shown in Figure 17. The focal mechanism is clearly different from the 1981 event mechanism as both SW and NW stations are dilatational. The first motion data

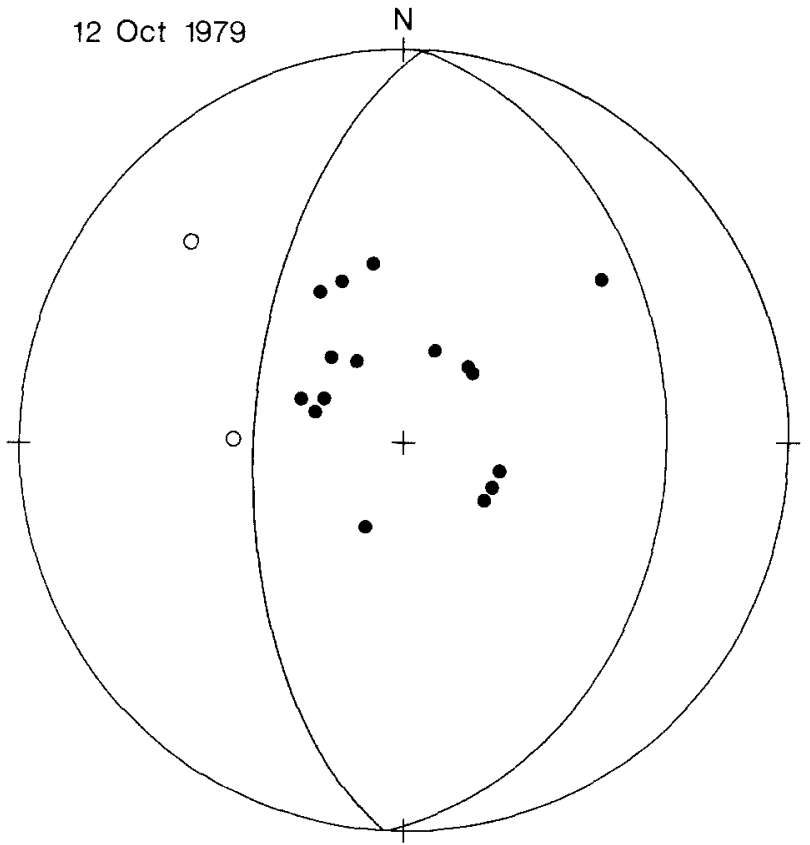

Figure 17

$P$ wave first motions and focal mechanism solution for the 12 OCT 1979 event. The strike and dip of the steeply dipping nodal plane are determined by moment tensor inversion and first motion data. The other nodal plane is then specified by fault plane inversion. 
only constrain the steeply dipping N-NE trending nodal plane. To determine the other nodal plane and the seismic moment, we use long-period Rayleigh waves. The IDA network was operating in 1979 and produced excellent long-period vertical component recordings of multiple orbit Rayleigh waves. We have applied the Kanamori and Given technique to these phases and obtained good results for the faulting geometry and the seismic moment. The constrained linear moment tensor inversion produces a thrust event with a fault strike of $3^{\circ}$. The first motion data constrain the west dipping plane to a dip of $58^{\circ}$. With these constraints on one nodal plane, the fault plane inversion determines a rake of $90.4^{\circ}$, i.e. pure thrust faulting, and a seismic moment of $0.6 \times 10^{27} \mathrm{dyn} \mathrm{cm}$. The $M_{W}$ for the 1979 event is then 7.1. Figure 18 shows the Rayleigh wave spectral amplitudes and phases with the fault inversion solution.

Investigations of the seismicity at many different subduction zones find focal mechanisms similar to that for the 1979 event with the shallow dipping nodal plane defining the fault plane. The aftershock distribution for the 1979 event supports the choice of the shallow dipping plane as the fault plane (see Figure 3). The largest one-day aftershocks define a roughly equant region that is $40-60 \mathrm{~km}$ across; the area represents a typical fault area for an event of this magnitude. The mainshock

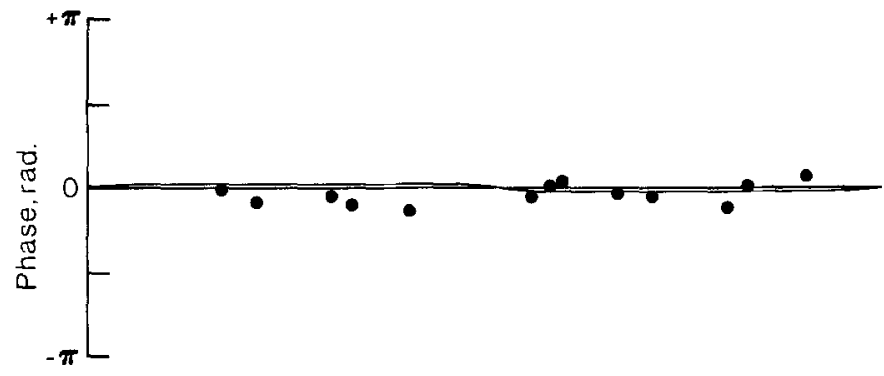

Rayleigh

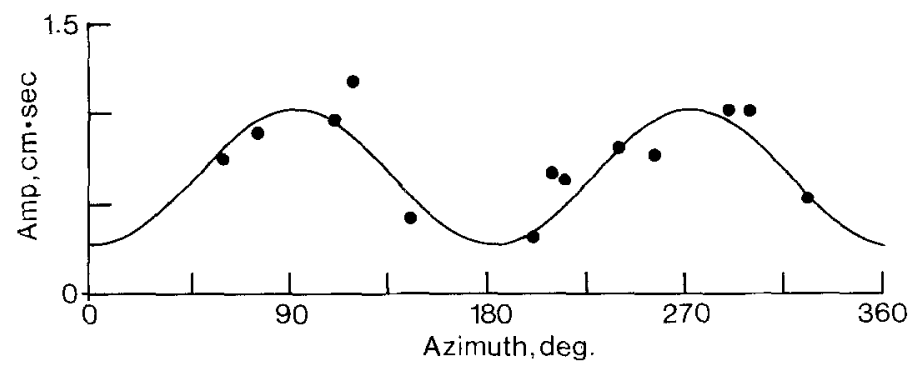

Figure 18

Rayleigh wave spectra and phase for the 12 OCT 1979 earthquake. The data (solid dots) are for a period of $256 \mathrm{~s}$ from R2 through R4 phases recorded by IDA stations. The fault plane inversion for depth of $33 \mathrm{~km}$ gives focal parameters of: $\phi=183^{\circ}, \delta=58^{\circ}$ (constrained), and $\lambda=90.4^{\circ}$, with a seismic moment of $6 \times 10^{26} \mathrm{dyn} \mathrm{cm}$. The amplitude and phase curves for this solution are plotted. 
hypocenter is at the downdip edge of the rupture area, another common characteristic of subduction events.

We have also studied the long period $P$ waves to determine the depth and moment release history for this event. Figure 19 shows the $P$ wave at SEO deconvolved at various depths. The depth extent of rupture is quite shallow, similar to the 1981 event. The source function at $40 \mathrm{~km}$ clearly displays the features of overestimating the depth, i.e., a complicated double-sided source function. The source functions above $10 \mathrm{~km}$ are all acceptable in terms of the simplicity criterion. We have used a point source depth of $5 \mathrm{~km}$ for source time fuction deconvolution. Figure 20 shows the source time functions. The seismic moment of the $P$ wave source time functions seems to be higher than the surface wave value. The 1979 event is a simple single pulse with a duration of $15 \mathrm{~s}$. With a rupture velocity of $3 \mathrm{~km} / \mathrm{s}$, this duration implies a fault extent of $45 \mathrm{~km}$ for a semi-circular rupture, once again a typical fault dimension for an earthquake of this size. If we assume a

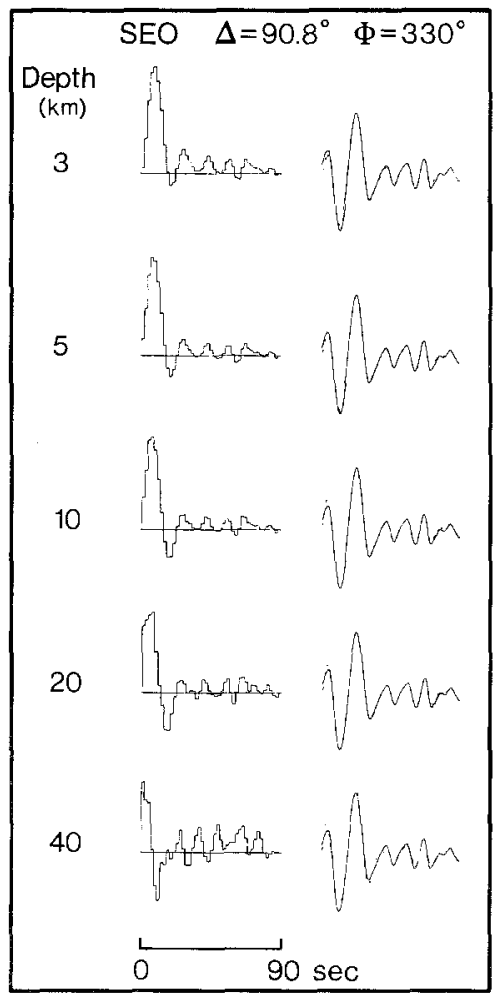

Figure 19

Focal depth test for the 12 OCT 1979 earthquake. The $P$ wave at SEO is deconvolved for assumed depths ranging from 3 to $40 \mathrm{~km}$. Water layer multiple bounces with a $1 \mathrm{~km}$ ocean depth are included in the Green's function. The simplicity criterion indicates a shallow depth of 3 to $10 \mathrm{~km}$. 


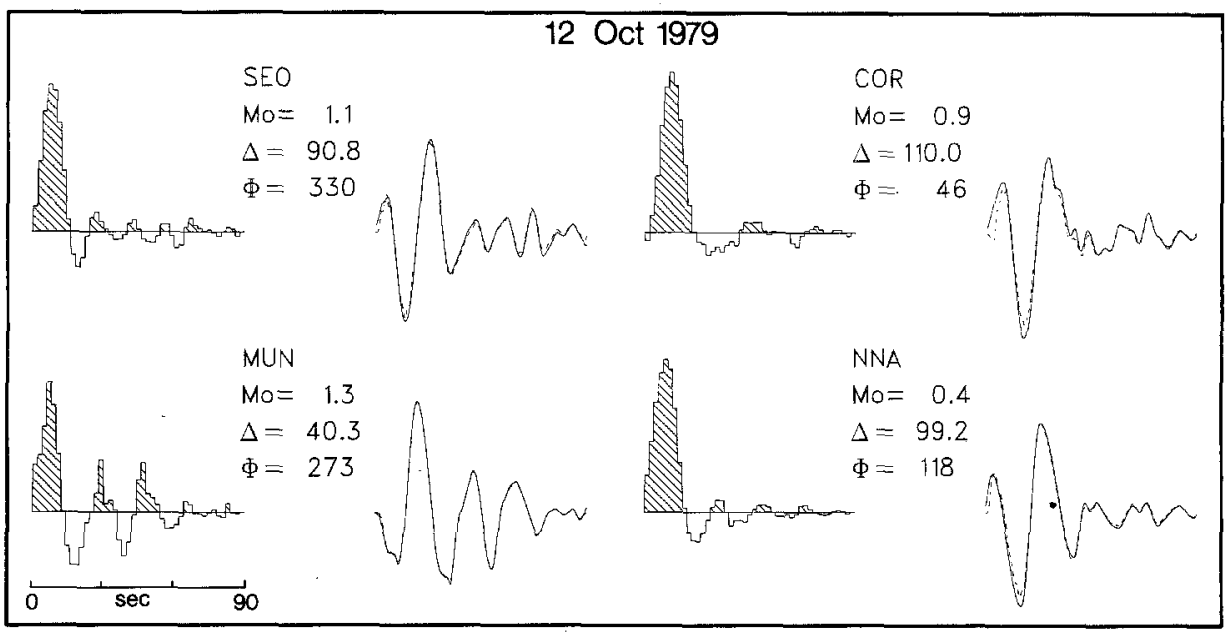

Figure 20

Source time functions for the 12 OCT 1979 event deconvolved from WWSSN long period $Z$ component records. Seismic moment $\left(\times 10^{27} \mathrm{dyn} \mathrm{cm}\right)$, distance, and azimuth are listed for each station. The point source is at a depth of $5 \mathrm{~km}$ and water layer multiples are included. These stations at different azimuths show a consistent simple pulse of moment release with $15 \mathrm{~s}$ duration.

fault area of $40 \times 60 \mathrm{~km}^{2}$ and a shear modulus of $3 \times 10^{11} \mathrm{dyn} \mathrm{cm}$, the seismic moment yields an average displacement of $0.8 \mathrm{~m}$.

If we assume that the 1979 earthquake is a repeat of the 1945 event, then the recurrence interval is 34 years and the thrust velocity component from the RM2 model gives an accumulated seismic displacement of $1.2 \mathrm{~m}$, within $50 \%$ of our above calculated displacement. Given the crude estimate of fault area, this approximate agreement between the seismic and cumulative displacement is consistent with the assumption that the 1945 and 1979 events ruptured the same fault area. Note that the recurrence interval between the 1918 and 1945 events is 27 years, hence it is possible that all three events ruptured the same thrust fault segment.

As previously noted, there is no indication of an anomalous stress drop in the aftershock area or rupture duration of the 1979 earthquake. The simple formula for the stress drop of a circular fault is: $\Delta \sigma=(7 \pi / 16) \mu(D / r)$, where $r$ is the fault radius. To calculate the stress drop, we use the above discussed seismic moment, shear modulus, and displacement, and a fault radius for a fault area of $2400 \mathrm{~km}^{2}$. These parameter choices result in a static stress drop of 12 bars, toward the lower end of observed stress drops. Although this value can clearly increase by a factor of two or more with refined fault area estimates, it will still fall within the band of typical stress drops for thrust events.

One global characteristic of subduction is underthrusting on a shallow dipping fault plane $\left(10^{\circ}\right.$ to $\left.30^{\circ}\right)$. Previous seismic evidence for subduction of the Australia 
plate beneath South Island include the scattered intermediate depth events in the southwestern corner of South Island and the thrust-type focal mechanism for the 1960 earthquake just off the Fiordland coast of South Island (see SCHOLz et al., 1973). Our study of the 1979 event demonstrates that shallow-dipping thrusting is also occurring south of the Fiordland coast, with the oceanic lithosphere of the Australia plate thrusting beneath the continental edge. While great underthrusting earthquakes at mature subduction zones extend to a depth of $40 \mathrm{~km}$, it appears that the 1979 underthrusting extends no deeper than $10 \mathrm{~km}$. Nevertheless, we conclude that there is active underthrusting at the northernmost tip of the Puysegur trench.

\subsection{The 11 JUN 1970 Hjort Trench Earthquake}

The 1970 earthquake (ISC parameters: origin time, 16:46:43.7, hypocenter $\left.58.86^{\circ} \mathrm{S} 157.6^{\circ} \mathrm{E} h=64 \mathrm{~km}, M_{s}=7.2\right)$ is the third largest event since 1963 in the Macquarie Ridge complex. It is the southernmost large event in the Hjort trench, and occurs only $300 \mathrm{~km} \mathrm{NW}$ of the PAC-ANT-AUS triple junction. It is located $30 \mathrm{~km}$ to the west of the bathymetric deep of the Hjort trench, which locally strikes at about $\mathrm{N} 20^{\circ} \mathrm{W}$. There are no long-period global digital network seismograms available for this event, and we have not used moment tensor inversion. Fortunately, the focal mechanism appears to be strike-slip and is thus well constrained by $P$ wave first motion data, though there are some complications. Figure 21 shows the

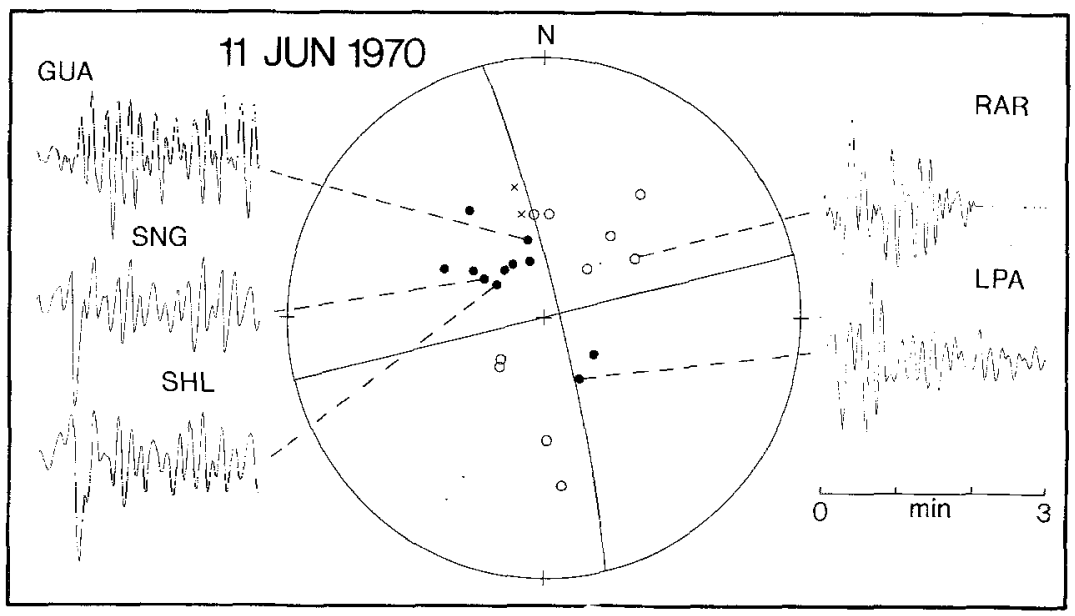

Figure 21

$P$ wave first motions, focal mechanism, and $P$ wave seismograms for the 11 JUN 1970 earthquake. The nodal plane with a strike of $346^{\circ}$ is chosen as the fault plane. This plane has a dip in the range of $80-90^{\circ}$. Selected $P$ waves, all recorded on WWSSN long period $Z$ components, are plotted. Note the emergent character of the $P$ wave which makes first motion determination difficult at many stations. The amplitude increases at about $20 \mathrm{~s}$ into the $P$ wave. Note that LPA displays a different waveform character. 
first motion data and the well constrained nodal planes. The strike of the NW trending plane is in close agreement with the local strike of the Hjort trench; hence it is reasonable to identify this plane as the fault plane. This choice for the fault plane gives right-lateral strike slip motion along this trend. There are no one-day aftershocks for the 1970 event listed in the ISC catalog.

The WWSSN long period $P$ waves plotted in Figure 21 show a rather complicated character. Most of the $P$ waves show an emergent arrival, making first motion determinations difficult. Careful consideration of the waveforms at noisy stations is necessary to avoid misreadings. The seismograms maintain a low amplitude for approximately $20-30 \mathrm{~s}$, then a strong arrival is seen at many stations, best exemplified by the break at SNG. After this large pulse, most of the stations show quasi-harmonic oscillations for up to three minutes. These oscillations are reminiscent of the oscillations in the WWSSN $P$ waves for the 1981 event. Due to the presence of these short period oscillations, we are unable to reliably deconvolve the WWSSN $P$ waves. Thus, the observed seismograms are smoothed before deconvolution. It appears that reliable and consistent source functions can be obtained by eliminating the shorter periods, with an important exception that will be discussed below. This implies that the Green's functions are not correct for the higher frequencies in the observed $P$ waves.

One curious feature of the ISC parameters for this event is the focal depth of $64 \mathrm{~km}$, determined by reported times of $p P-P$. Looking at the seismograms in Figure 21 , it seems rather unlikely that a $p P$ phase could be reliably identified. We have used the RAR $P$ wave to perform the focal depth test as this station is relatively insensitive to small changes in the focal mechanism. It is immediately obvious that the focal depth is above $40 \mathrm{~km}$ (Figure 22), thus the ISC depth is incorrect. The simplicity criterion indicates that either 3 or $5 \mathrm{~km}$ is the best point source depth. Hence this is a shallow event, typical of strike-slip events in the Macquarie Ridge and elsewhere.

We have deconvolved source time functions from the filtered WWSSN longperiod $P$ waves. Figure 23 shows the results for the focal mechanism of Figure 21 and a focal depth of $5 \mathrm{~km}$. The average seismic moment from the time functions is about $1 \times 10^{27}$ dyn $\mathrm{cm}\left(M_{W} \approx 7.3\right)$, crudely consistent with the $M_{s}$ value. The long period part of the moment release shows a single pulse with an emergent ramp-type onset and a rather abrupt truncation. Sharp truncations of the moment release have been observed for several large earthquakes (e.g., BECK and RUFF, 1985; SCHWARTZ and RUFF, 1985). This truncation is responsible for the major pulse in the seismograms at about $20 \mathrm{~s}$.

The LPA seismogram shows a completely different character. Note that the $P$ wave onset at LPA is relatively larger than at the other stations. The arrival time has been checked, and it would appear that this is a real feature. Moreover, the $P$ wave at NNA displays the same character as LPA. It is not surprising then that the source time function at LPA shows a completely different character than the other 


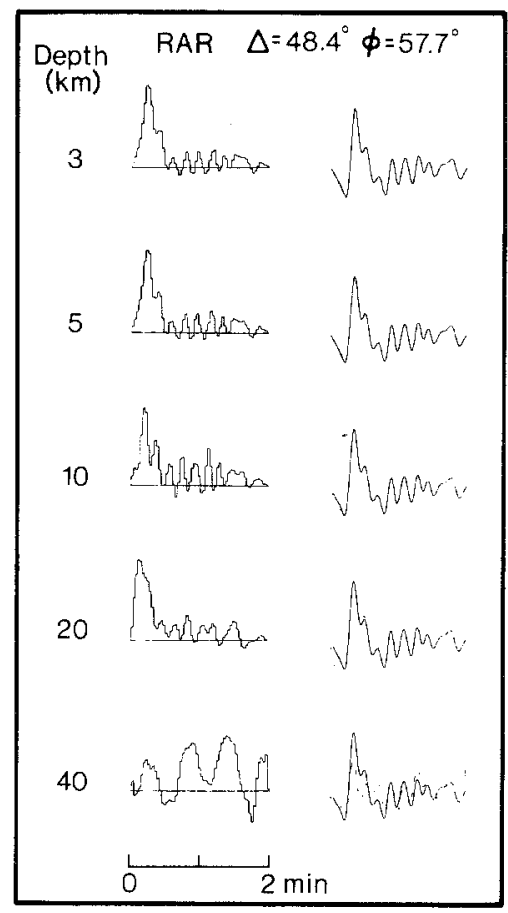

Figure 22

Focal depth test for the 11 JUN 1970 earthquake. The long period $Z$ component at RAR is deconvolved at assumed depths ranging between 3 and $40 \mathrm{~km}$. Water bounces from a $4 \mathrm{~km}$ ocean thickness are included, and the fault plane dip is $90^{\circ}$. The observed $P$ wave is filtered to largely remove periods shorter than $6 \mathrm{~s}$. The simplicity criterion indicates a shallow focal depth, perhaps $5 \mathrm{~km}$.

stations. There is an obvious explanation for this discrepancy: we do not have mutually consistent Green's functions for all the stations. Given that the character of the other seismograms is widely observed at different azimuths, we prefer to interpret LPA as "anomalous". Since NNA seems to share this anomalous character, we cannot simply dismiss it as a seismograph problem or a nodal phenomenon. One possible cause of this anomalous behavior is some change in the focal mechanism that effects the SE quadrant more than the other quadrants of the focal sphere. At this time however, we are not able to suggest, much less prove, a focal mechanism change that reconciles all the observations. We can only issue a caution that moment release might have occurred with faulting geometry different from the first motion mechanism. Thus, the rupture process of the 1970 earthquake presents complications at all periods: short periods have the quasi-harmonic oscillations and the long periods are not mutually consistent at all azimuths. Since some fraction of the moment release occurred with the geometry of the first motion mechanism, the RM2 predicted motion is correct insofar as the sense of strike-slip motion is concerned. This lends some support to the notion that the PAC-AUS plate boundary follows the Hjort trench. 


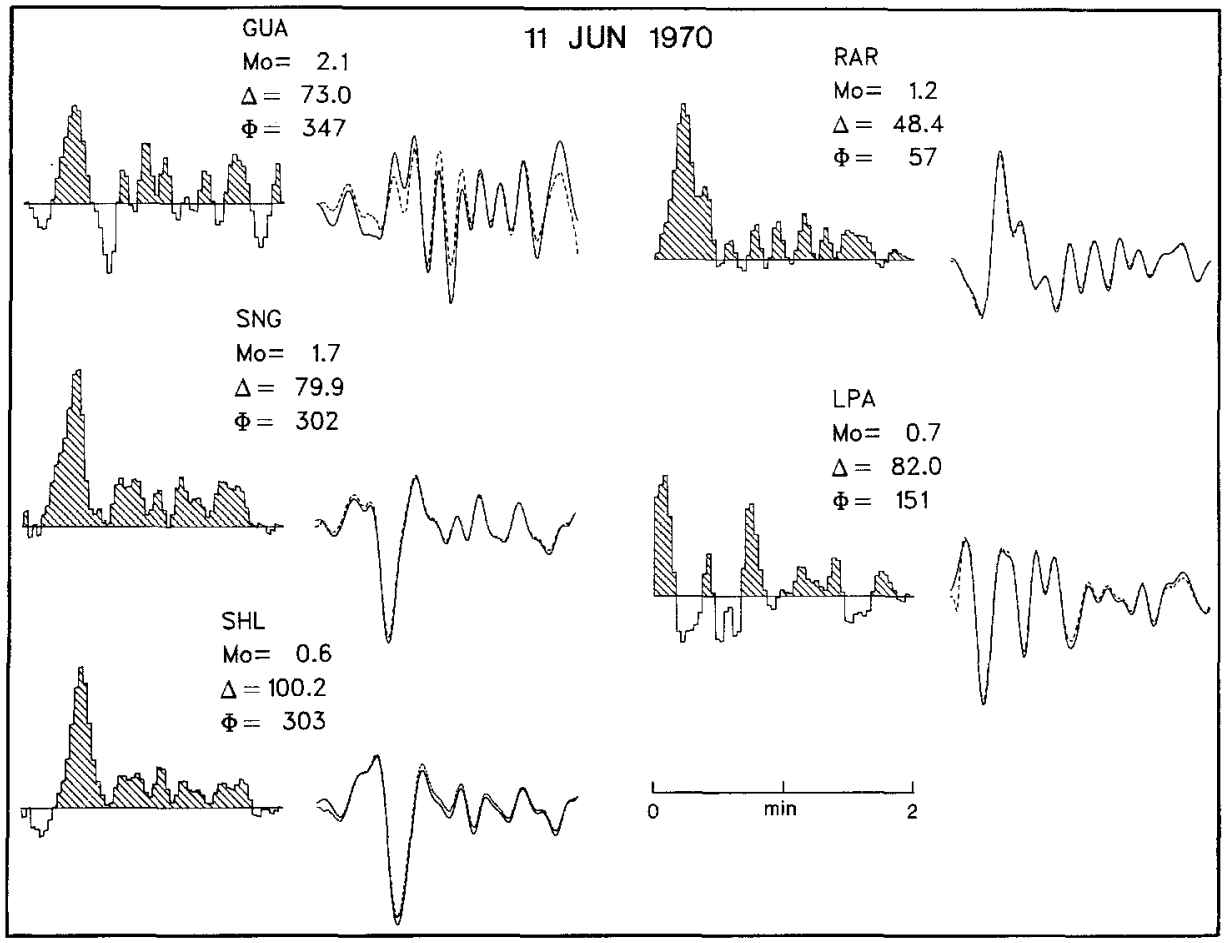

Figure 23

Source time functions for the 11 JUN 1970 earthquake deconvolved from filtered long period $P$ wave seismograms. The effect of the smoothing filter can be seen by comparing the filtered traces to the observed traces in Figure 21. The source functions are mostly coherent in the long period band with a single large pulse of moment release, LPA is the obvious exception. Seismic moment has units of $10^{27} \mathrm{dyn} \mathrm{cm}$.

\subsection{Focal Mechanisms of Smaller Post-1963 Events}

We report the focal mechanisms of smaller earthquakes that have been determined by other investigators. These determinations are based on two different procedures: first motion focal mechanisms and long-period moment tensor inversion. All mechanisms for the post-1963 earthquakes are listed in Table 1.

3.4.1. First motion focal mechanisms. We have found three sources of first motion mechanisms for Macquarie Ridge earthquakes, SYkes (1967), BANGHAR and Sykes (1969), and Johnson and MolNAR (1972), for a total of five earthquakes. In general, the steeply dipping planes of these mechanisms are well constrained, while shallow dipping planes are somewhat uncertain. Hence, the strikes of the shallow dipping "fault planes" for the thrust events are not well determined, but the strike slip mechanisms and the slip vector orientation for the thrust events are generally reliable. Three of these focal mechanisms are for events 
Table 1

Summary of focal mechanisms for Macquarie Ridge Complex earthquakes.

\begin{tabular}{|c|c|c|c|c|c|c|c|c|c|c|}
\hline \multirow[b]{2}{*}{$\#$} & \multirow[b]{2}{*}{ Date } & \multicolumn{2}{|c|}{ Epicenter } & \multirow[b]{2}{*}{ Depth } & \multirow[b]{2}{*}{ Mag } & \multicolumn{4}{|c|}{ Focal Mech } & \multirow[b]{2}{*}{$\operatorname{Re}$} \\
\hline & & Lat $\left({ }^{\circ} \mathbf{S}\right)$ & $\operatorname{Lon}\left({ }^{\circ} \mathrm{E}\right)$ & & & $P$ & $\phi$ & $\delta$ & $\lambda$ & \\
\hline 1 & 12 SEP 1964 & 49.0 & 164.5 & $\mathrm{~S}$ & 6.9 & A & 173 & 58 & (68) & $\mathrm{S}$ \\
\hline 2 & 8 NOV 1964 & 49.0 & 164.2 & $\mathbf{S}$ & 5.6 & A & 146 & 78 & (90) & BS \\
\hline 3 & 2 AUG 1965 & 55.9 & 157.7 & $\mathrm{~S}$ & 6.6 & $\mathbf{F}$ & 184 & 84 & 210 & BS \\
\hline 4 & 25 MAY 1966 & 52.8 & 160.2 & $\mathrm{~S}$ & 6.5 & $?$ & $(168)$ & (36) & $(90)$ & BS \\
\hline 5 & 20 SEP 1967 & 49.6 & 163.9 & $\mathrm{~S}$ & 6.1 & A & 191 & 72 & $(90)$ & $\mathrm{JM}$ \\
\hline 6 & 11 JUN 1970 & 58.9 & 157.6 & 5 & 7.2 & $\mathrm{~F}$ & 346 & 85 & 180 & * \\
\hline 7 & 12 OCT 1979 & 46.5 & 165.9 & 5 & 7.4 & $\mathrm{~F}$ & 3 & 32 & 90 & * \\
\hline 8 & 7 FEB 1980 & 54.2 & 158.8 & $\mathrm{~S}$ & 6.5 & $\mathrm{~F}$ & 20 & 90 & 186 & * \\
\hline 9 & 25 MAY 1981 & 48.6 & 164.7 & 10 & 7.6 & $\mathrm{~F}$ & 30 & 70 & 173 & * \\
\hline 10 & 27 JUN 1982 & 55.4 & 160.2 & $\mathrm{~S}$ & 6.1 & $\mathrm{~F}$ & 214 & 85 & 134 & $\mathrm{H}$ \\
\hline$\| 1$ & 7 JUL 1982 & 51.1 & 160.6 & $\mathrm{~S}$ & 7.0 & $F$ & 63 & 78 & 193 & $\mathrm{H}$ \\
\hline 12 & $23 \mathrm{MAY} 1984$ & 52.0 & 161.1 & $\mathrm{~S}$ & 5.9 & $\mathrm{~F}$ & 211 & 34 & 122 & $\mathrm{H}$ \\
\hline 13 & 2 JUL 1984 & 54.9 & 158.9 & $\mathrm{~S}$ & 5.0 & $\mathbf{F}$ & 19 & 90 & 180 & $\mathrm{H}$ \\
\hline 14 & 3 JAN 1985 & 54.4 & 155.4 & $\mathrm{~S}$ & 5.1 & $?$ & 240 & 84 & 160 & $\mathrm{H}$ \\
\hline 15 & 31 JAN 1985 & 46.1 & 165.1 & $\mathrm{~S}$ & 6.1 & A & 197 & 66 & 95 & $\mathbf{H}$ \\
\hline
\end{tabular}

Epicentral parameters are ISC values through 1982, NEIS for 1984 and 1985. Magnitude is USCGS $m_{b}$ through $1967, M_{s}$ afterwards. Shallow hypocentral depth is indicated by 'S'. Numerical depth values are in $\mathrm{km}$, and are determined by $P$ wave analysis. The focal mechanism parameters are strike, dip, and rake, in degrees, for the standard convention (see KANAMORI and GIVEN, 1981). The ' $P$ ' column refers to which nodal plane is described, ' $F$ ' is the fault plane and ' $A$ ' is the auxiliary plane in our interpretation. For first motion mechanisms, we describe the best-constrained plane. Unreliable values are given in parentheses. The focal mechanism references are: S, SYkeS, 1967; BS, BANGHAR and Sykes, 1969; JM; Johnson and MOLNAR, 1972; H, the Harvard group, see ISC catalog; ${ }^{*}$, this study.

that occur in the cluster of seismicity between $49^{\circ} \mathrm{S}$ and $50^{\circ} \mathrm{S}$ (we will refer to this seismicity cluster as the "1981 cluster"), and all three events show thrust mechanisms. We assume that the east-dipping nodal planes are the fault planes. The azimuths of the poles to the auxiliary planes for these three events are $\mathrm{N} 56^{\circ} \mathrm{E}$, $\mathrm{N} 83^{\circ} \mathrm{E}$, and $\mathrm{N} 101^{\circ} \mathrm{E}$. Since the intermediate orientation is from the largest event, we use a slip vector orientation of $\mathrm{N} 83^{\circ} \mathrm{E}$ as representative of the thrust motion in the 1981 cluster. The 25 MAY 1966 earthquake has compressional first motions in the center of the focal sphere and is therefore a thrust event, but the nodal planes are free to rotate to any strike. The 2 AUG 1965 event is a right lateral strike-slip event along the northerly plane and is well constrained by first motions. We will discuss this event in a later section. There is one MRC earthquake studied by BANGHAR and SYKes (1969) that is not listed in Table 1, the 12 MAY 1963 event. Their first motion data suggest a vertical dip-slip mechanism, although it is poorly constrained. The epicenter is $150 \mathrm{~km}$ to the east of the MRC and the ISS depth is listed at $70 \mathrm{~km}$. These parameters suggest that this earthquake may be an intraplate event 
in a subducted slab. Only a few good quality seismograms are available for this event due to its small magnitude. A comprehensive $P$ wave study is not possible, but preliminary analysis of the $P$ waves at close stations indicate that this earthquake is in fact shallow. A shallow depth removes the speculation of a slab event.

3.4.2. Moment tensor inversion focal mechanisms. Several reliable focal mechanisms in the MRC have been determined as part of systematic global studies. As an early experiment in the systematic application of moment tensor inversion, KANAMORI and GIVEN (1981) inverted the long-period Rayleigh waves recorded by IDA stations to determine the constrained moment tensor for large events that occurred in 1980; their event list includes one event in the Macquarie Ridge complex. The 7 FEB 1980 event (ISC parameters: origin time, 10:49:16.3, hypocenter $54.2^{\circ} \mathrm{S} 158.8^{\circ} \mathrm{S} h=10 \mathrm{~km}, M_{s}=6.5$ ) is located just $40 \mathrm{~km}$ north of Macquarie Island along the crest of the northeast striking bathymetric high. The constrained moment tensor solution in Kanamori and Given is a strike-slip mechanism with right lateral slip along a plane that trends $\mathrm{N} 20^{\circ} \mathrm{E}$; this trend coincides with the local strike of the Macquarie Ridge. To check this solution, we have used $P$ waves recorded by GDSN stations. We find that only a minor modification of the Kanamori and Given focal mechanism is necessary. The first motion data and a few

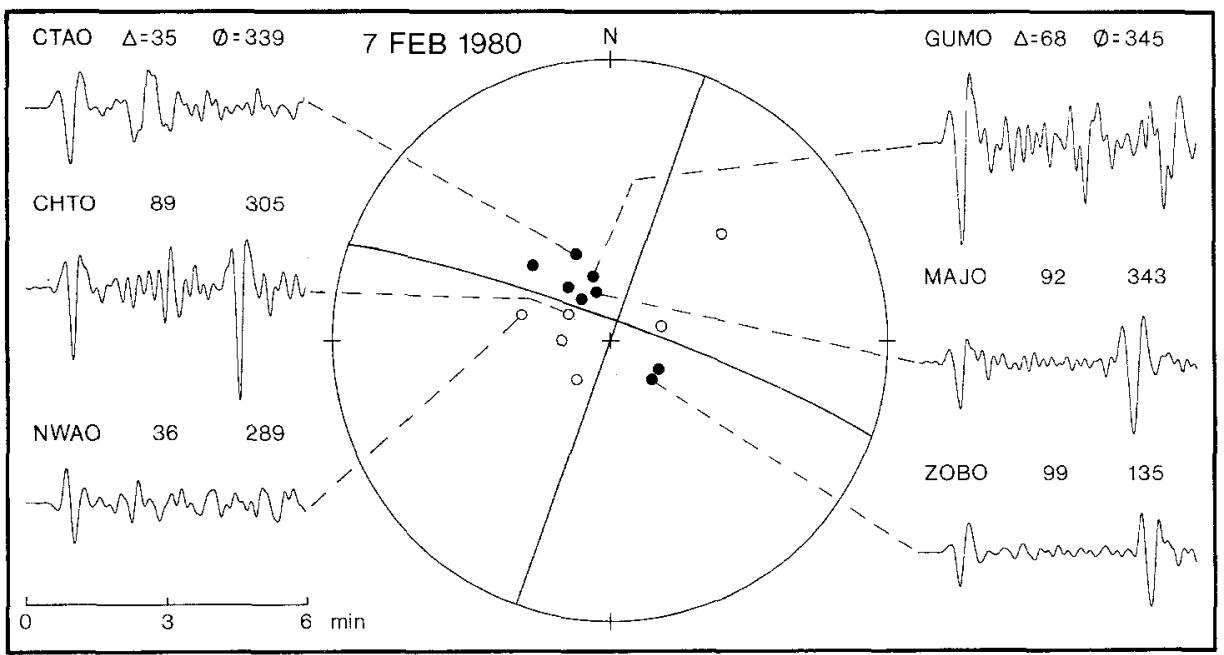

Figure 24

Focal mechanism, $P$ wave first motions, and GDSN $P$ waves for the 7 FEB 1980 earthquake. Station code, distance and azimuth (in degrees) are listed for these $Z$ components. The moment tensor inversion gives a major double couple of right lateral strike-slip along a trend of $N 20^{\circ} \mathrm{E}$. The first motion data require only a minor modification, a rake of $186^{\circ}$ rather than $180^{\circ}$. The long period GDSN $P$ waves show single simple pulses. The traces start $30 \mathrm{~s}$ before the $P$ wave arrival, and the $P P$ phase follows the $P$ wave. 
$P$ wave seismograms are plotted in Figure 24 along with the modified focal mechanism. The 1980 event appears to be a simple shallow earthquake.

The Harvard group systematically inverts for the moment tensors of events that are well recorded by the GDSN, their solutions are now routinely published in the NEIS and ISC listings. Their catalog of solutions is fairly complete for events with magnitude larger than $5 \frac{1}{2}$ from 1981 to the present, and they have extended the catalog back to 1977. A total of six earthquakes, excluding the 25 MAY 1981 event, in the Macquarie Ridge complex are in their post-1981 catalog. We have not checked any of these solutions, but given the excellent correspondence for the faulting geometry of the large 1981 event, our opinion is that the nodal planes are well determined. These six events are distributed along the Macquarie Ridge complex and include both strike-slip and thrust earthquakes. The focal mechanisms for these earthquakes are listed in Table 1. We will discuss these focal mechanisms in conjunction with all the MRC focal mechanisms in the following section.

\subsection{Discussion of Post-1963 Seismicity}

The focal mechanisms and locations for the entire list of post-1963 earthquakes are plotted in Figure 25 along with the simplified bathymetry of the MRC. The earthquakes are identified by numbers that correspond to the listing in Table 1. One curious feature of the mechanisms in Figure 25 is the interspersed occurrence of both strike-slip and thrust earthquakes. If we focus our attention on the 1981 cluster, we see that the smaller thrust events are located adjacent to the 1981 fault zone. The slip vector strike of $\mathrm{N} 83^{\circ} \mathrm{E}$ for thrusting is markedly different than the $\mathrm{N} 30^{\circ} \mathrm{E}$ strike for the 1981 event slip vector. Any estimate of the relative plate motion in this region based solely on the smaller thrust events would be incorrect. Thus, we must be cautious when using any single earthquake along the Macquarie Ridge as an indicator of the local plate motion. We can view the slip vectors from strike-slip and thrust events in the same region as extremal bounds on the direction of plate motion.

There are two events to the north of the 1981 cluster. Event $\# 7$ is the 12 OCT 1979 earthquake that we have discussed in detail, event \#15 is a smaller event that also shows shallow-dipping underthrusting to the east. This latter event is too small to represent a repeat of the 1979 event and its location is to the west of the 1979 event. There are two thrust mechanisms in the McDougall trough region $\left(52 \frac{1}{2} \mathrm{~S}\right)$ to the south of the 1981 cluster. Unlike the 1979 mechanism, these focal mechanisms imply underthrusting to the west. While mechanism \#4 is not reliable, mechanism \# 12 is a Harvard CMT solution. A switch in the "polarity" of underthrusting is thus associated with the alternation of the troughs and rises between the Puysegur and McDougall regions. Although we would also anticipate west-dipping underthrusting along the small trough to the east of Macquarie Island $\left(54 \frac{1}{2}^{\circ} \mathrm{S}\right)$, there are only two strike-slip mechanisms in this region. Note that the Harvard CMT solution for 


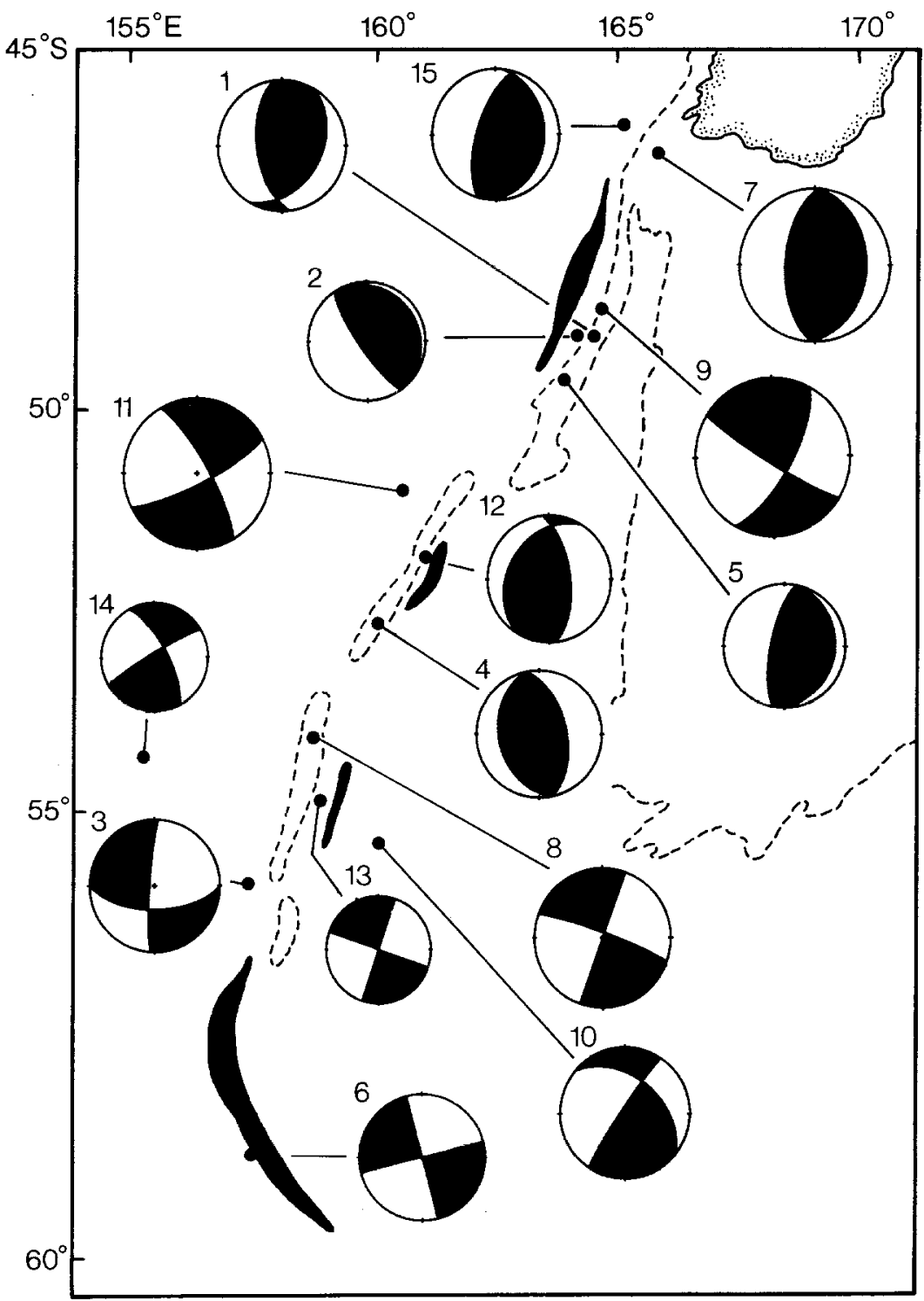

Figure 25

Focal mechanisms for Macquarie Ridge earthquakes and the primary physiographic features. All reliable mechanisms for post-1963 events are shown, the numbers refer to the event number in Table 1, and the dots show the epicentral locations from Table 1 . The focal sphere size is proportional to event magnitude, and the compressional quadrants are shaded in these lower-hemisphere equal-area projections. The dashed lines show the 1000 fathom depth contours, while the troughs along the Macquarie Ridge are shaded (delineated by the 2600 fathom depth contours, from MAMmEricks et al., 1975). Part of South Island is at the upper right. The shallow shelf to the east is the Campbell Plateau. The two large troughs are the Puysegur trench to the north and the Hjort trench in the south; two smaller troughs between $50^{\circ} \mathrm{S}$ and $55^{\circ} \mathrm{S}$ are to the east of the ridge. Oblique convergence is accommodated by a dual-rupture mode of strike-slip and thrust earthquakes. 
event \# 13 has the same fault strike as the 7 FEB 1980 earthquake discussed above (event \#8). One implication of these events is that the seismically defined plate boundary is along, or slightly to the east of, the bathymetric rise between $52^{\circ} \mathrm{S}$ and $55^{\circ} \mathrm{S}$. To the south, the strike-slip events of 2 AUG 1965 (\#3) and 11 JUN 1970 (\#6) both plot slightly to the west of the MRC.

There are three events in Figure 25 that plot off the main bathymetric trend of the MRC, events \#10,\#11, and \#14. The two smaller events in the Macquarie Island region $(\# 10, \# 14)$ are clearly displaced to either side of the MRC and represent intraplate seismicity. The mechanisms show right lateral strike-slip along northeast trending planes, hence they exhibit the same basic deformation as the slip along the PAC-AUS boundary. The large off-MRC event at $51^{\circ} \mathrm{S}$ (\#11) deserves more emphasis. This event is located in the seismicity gap between the 1981 cluster and the McDougall trough. This seismicity gap corresponds to an offset in the bathymetric rise, and the alternation of the troughs. Perhaps the 1982 event occurs along an ancient zone of weakness that is associated with the MRC offset. Note that the right lateral motion for this event occurs along the nodal plane striking at $\mathrm{N} 63^{\circ} \mathrm{E}$. This fault strike is significantly different from the $\mathrm{N} 30^{\circ} \mathrm{E}$ fault strike of the large 1981 event. Thus the slip vector for the 1982 event points in a direction intermediate to the strike-slip and thrust slip vectors in the 1981 cluster. The slip vector for the 1982 event may reflect the "true" PAC-AUS relative motion.

The seismicity gaps are interesting features. The 1981 cluster seems to be bounded by zones of reduced seismicity to the north and south. With active subduction and the occurrence of three large earthquakes in the northernmost Puysegur trench, the seismicity gap in the central portion of the Puysegur trench is particularly puzzling. Is this region a seismic gap, or is it possible that some of the surrounding pre-1963 earthquakes are actually located in this quiet region? Many of the historical earthquakes are poorly located and large shifts in their location are possible. Note that two of the large events in the northern MRC (1924 and 1926) are located off the main bathymetric expression of the Macquarie Ridge complex. Are these events mislocated, or is there significant intraplate seismic activity to the west? To complement the study of the recent large earthquakes, we have checked the locations of the pre-1963 large earthquakes and have even found focal mechanism information for two earthquakes.

\section{Pre-1963 Large Earthquakes}

Of the 15 large events in the Macquarie Ridge complex, 10 occurred before the establishment of the WWSSN. It is difficult to study these events as there is no centralized data archive of high-quality seismograms. Since many of the early seismographs were not well-calibrated, wave amplitude or waveshape studies are difficult. Even the polarity of many of the seismographs is not known. Station timing 
errors can also introduce significant travel time residuals. Despite all these pitfalls, we have systematically tested the epicentral locations of all large earthquakes in the MRC, and are able to place constraints on the faulting geometry for two events.

\subsection{Epicenter Relocation}

While most of the seismicity plots along the main bathymetric features of the MRC, two of the large earthquakes in Figure 1, the 24 JUL 1924 and 3 OCT 1926 events, plot west of the Puysegur trench. A major discontinuity in the oceanic lithosphere lies between the Puysegur trench and the intersection of the Balleny fracture zone with the southern edge of the Tasman plateau. This discontinuity is associated with the change in spreading direction at $50 \mathrm{Ma}$ (before present) from the older Tasman sea opening to the present-day Australia-Antarctica opening (WeIsSEL et al., 1977). A large earthquake occurred 1 MAY 1951 along the Balleny fracture zone, and thus might be associated with the Puysegur-Balleny trend. The oceanic lithosphere between the MRC and the Balleny fracture zone is a rather narrow southward extension of the AUS plate that is bounded to the west and east by the ANT and PAC plates, respectively. Thus it is possible that the region between the MRC and the Balleny fracture zone is a mini-plate that is decoupled from the AUS plate along the Puysegur-Balleny trend. Although a few events have occurred along this trend since 1963, they are small events and the focal mechanisms have not been determined. Our analysis is thus limited to relocations of the above-mentioned three large events.

The ISS locations for the 24 JUL 1924 and 3 OCT 1926 events are quite different from the locations plotted in Figure 1. Epicenters for the pre-1950 large events are from GUTENBERG and RichTER (1949); both the 1924 and 1926 events are shifted by about $150 \mathrm{~km}$ from the ISS locations. Epicentral shifts of this magnitude are not uncommon for relocations of earthquakes from the early part of this century. Gutenberg's personal notes (available through the Seismological Laboratory, Caltech, Pasadena, CA 91125) show his relocation procedure: he simply plotted travel time residuals from the ISS bulletins as a function of event-station azimuth and subjectively sketched a sinusoidal curve through the residuals. Since we are not endowed with the subjective skills of Gutenberg, we have quantified this procedure as a simple check on the locations of all large MRC events. Modern relocation techniques are quite sophisticated (see e.g., DEwEY and SPENCE, 1979) and offer relative epicentral locations accurate to $10 \mathrm{~km}$ or less. However, we retain a simple one-step method as we are mainly interested in much larger epicentral shifts. We have used the $P$ arrival times as reported in the ISS bulletins. There are at least two reasons that we might expect to improve upon the ISS locations: (1) the use of modern, i.e., more accurate, travel time tables, and (2) the computational ease of testing epicentral perturbations to find the best-fit location. We have also used a subset of the data reported in the bulletins; we do not 
use diffracted $P$ waves or core phases. Our selection results in fewer data, though the selected residuals are possibly more reliable.

4.1.1. Method. We use a simple relocation method that has been used by many seismologists for decades. Although this method is quite straightforward and well-known, we describe our procedure in detail for the sake of completeness.

The quantitative scheme is based on the simple first-order linearization of the travel time function for teleseismic $P$ waves. The $P$ wave arrival time observed at station $i$ is obs $T_{i}$. The calculated $P$ wave time depends on three parameters: origin time, depth, and epicentral distance $\left(t, h\right.$, and $x_{i}$, respectively). For an initial hypocentral location and origin time, we find the initial epicentral distance and calculate the travel time residual: $r_{i}={ }_{\text {obs }} T_{i}-T\left(t_{0}, h_{0},{ }_{0} x_{i}\right)$. We seek perturbations to the initial hypocentral parameters to reduce the residuals. The perturbation to epicentral location must be rewritten in terms of the perturbation in epicentral distance to the stations. If the epicenter moves a distance $(d y)$ along a direction $(\theta$ is the angle relative to north), then the first-order relation for the travel time variation with respect to epicentral distance variation $\left(d x_{i}\right)$ can be written in terms of the epicentral perturbation: $\left(\delta T / \delta x_{i}\right) d x_{i}=-(\delta T / \delta y)_{i} \cos \left(\phi_{i}-\theta\right) d y$, where $\phi_{i}$ is the event-station azimuth relative to north. The derivative $(\delta T / \delta y)_{i}$ is evaluated at the initial distance and is simply the ray parameter, $p_{i}$. Define the residuals for the perturbed epicentral location as $d T_{i}$, where $d T_{i}={ }_{\text {obs }} T_{i}-T\left(t_{0}+d t, h_{0}+d h\right.$, ${ }_{0} x_{i}+d x_{i}$ ). Expand the travel time function as a Taylor expansion about the initial parameters, retain only the first-order linear terms, and replace $\left(\delta T / \delta x_{i}\right) d x_{i}$ with the above expression to obtain: $d T_{i}=\left[{ }_{\text {obs }} T_{i}-T\left(t_{0}, h_{0},{ }_{0} x_{i}\right)\right]-d t-(\delta T / \delta h)_{i} d h+p_{i}$ $\cos \left(\phi_{i}-\theta\right) d y$. Since we cannot resolve changes in the hypocentral depth with our data, we combine the time shift due to depth perturbation with the origin time shift. The expression in brackets is $r_{i}$, the observed travel time residual, hence we now have: $d T_{i}=r_{i}-d t+p_{i} \cos \left(\phi_{i}-\theta\right) d y$. The parameter perturbations, $d t$ and $d y$, are linearly related to the residuals for a specified $\theta$. The sum of the squares of residuals $d T_{i}$ is minimized with respect to $d t$ and $d y$ by the least squares straight line through $r_{i}$ plotted as a function of $p_{i} \cos \left(\phi_{i}-\theta\right)$. The intercept and slope of the least squares line through $r_{i}$ are $d t$ and $-d y$, respectively. Note that since the distance perturbation is given by the slope of the best-fit line to the residuals, the slope standard error is a measure of the distance uncertainty. We consider the epicentral relocation significant only if the standard error along the relocation direction is substantially less than the relocation distance, i.e., the slope is significantly different from zero. Since we do not know the best direction for the epicentral perturbation in advance, we try all directions, in $10^{\circ}$ increments, and choose the direction that produces the best overall fit to the residuals. Although the relocated epicenters listed in Table 2 are quantitatively determined, our error analysis is rather simple and not completely rigorous. Thus, the listed uncertainties in latitude and longitude represent conservative subjective estimates. 


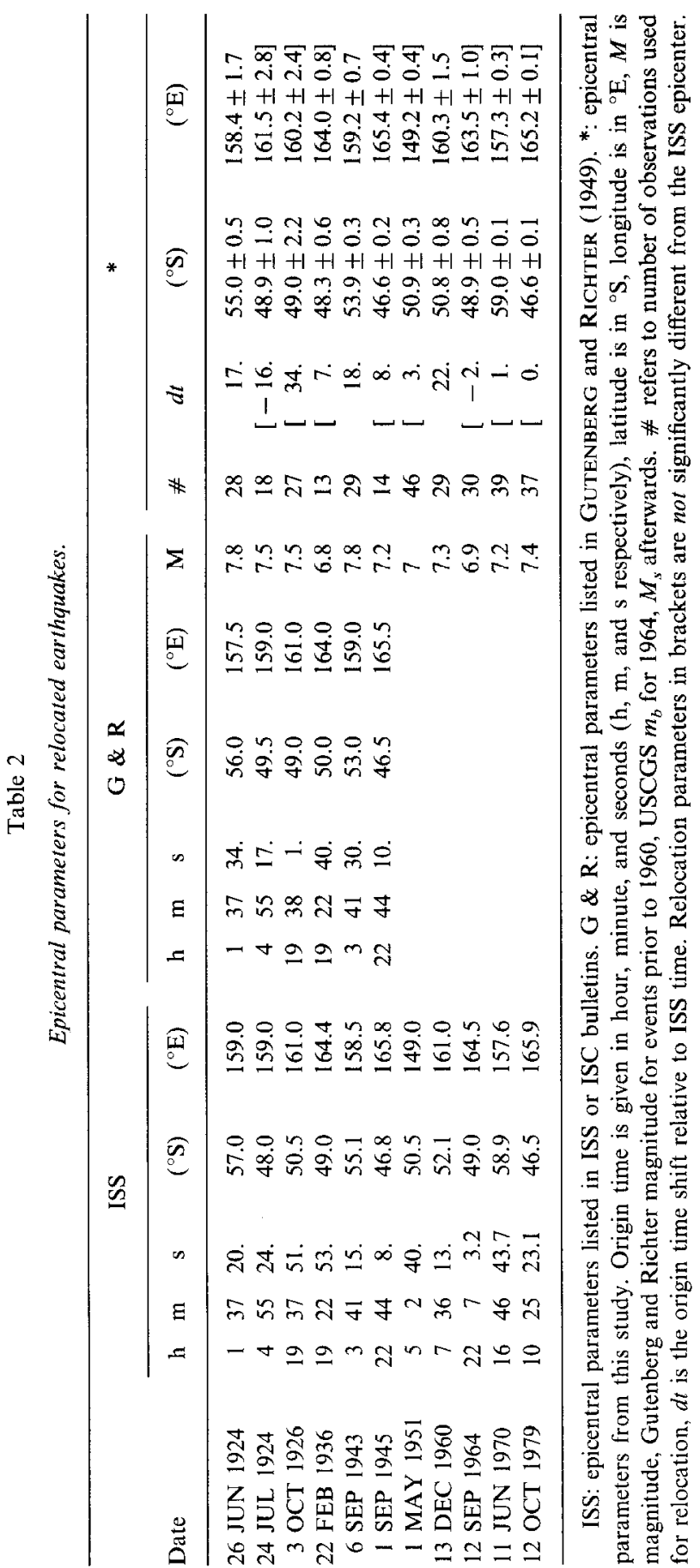


4.1.2. Relocation results. All relocations are relative to the ISS parameters. We recompute the station distance, azimuth, and $P$ wave travel time based on the Jeffreys-Bullen tables. We apply this procedure to all large pre-1963 events along the MRC, to the 1951 event south of Tasmania, and to three post-1963 large events (see Table 2). The locations of the 1964, 1970, and 1979 events are tested to determine the bias and resolution limit of the simple relocation scheme for MRC events. Our procedure moves these events in different directions by $50 \mathrm{~km}$ or less. Thus, in addition to the standard error criterion, a relocation is not considered significant unless the relocation distance is greater than $50 \mathrm{~km}$. Given these two criteria, we obtain significant relocations for three pre-1963 events. The events are discussed in chronological order.

The relocation of the 24 JUN 1924 event is significant, the epicenter moves $230 \mathrm{~km}$ northwest of the ISS location. The epicenter listed in Table 2 is along the MRC, though somewhat north of the locations of MACELWANE (1930) and Gutenberg. In the Puysegur trench region, we do not obtain significant relocations for either the 1924 or 1926 events. Though the best-fit locations are more than $100 \mathrm{~km}$ from the ISS locations, the standard errors include the initial epicenters. The relocation directions are to the south for the 1924 event and to the north for the 1926 event, the same directions as for Gutenberg's relocations. While the locations for these two events obtained by Gutenberg, the ISS, and our study are all to the west of the MRC, our error limits for both events extend to the MRC. Thus, we cannot reach a strong conclusion regarding the locations of these two events, but it is certainly possible that they are located west of the MRC. There is no significant relocation of the 1936 event in the 1981 seismicity cluster. Gutenberg's relocation for the 1943 event is more than $200 \mathrm{~km}$ north of the ISS epicenter; we obtain a significant relocation for the 1943 event that is also north of the ISS epicenter, though with a displacement of only $150 \mathrm{~km}$. This relocation simply moves the 1943 event along the trend of the MRC. The relocations for the 1945 and 1951 events are not significant, the displacements are less than $50 \mathrm{~km}$. Thus, the 1945 event occurred quite close to the 12 OCT 1979 event, and the 1951 event does indeed occur along the Balleny fracture zone. The relocation of the 13 DEC 1960 event is probably the most significant result of our relocation study. The relocated epicenter is displaced $160 \mathrm{~km}$ along a direction of $\mathrm{N} 20^{\circ} \mathrm{W}$ from the ISS epicenter. This places the 1960 event in the low-level seismicity region south of the 1981 cluster, virtually the same location as the 7 JUL 1982 event. Thus, the occurrence of two large events in this "quiet" region implies continued slip in this region and underlines the importance of the 1982 focal mechanism. The focal mechanism of the 1960 event will be discussed in the next section.

The epicenters for all large earthquakes that we have considered are along the MRC except for the 1 MAY 1951 event and possibly the 24 JUL 1924 and 3 OCT 1926 events. We have searched the seismicity catalogs for other large events along the Puysegur-Balleny trend but have found none. There are a few very small events, but they do not define an obvious linear trend. 


\subsection{Focal Mechanisms}

Reliable determinations of first motion focal mechanisms usually require a global seismogram collection with known instrument polarities and good azimuthal coverage. Due to special circumstances, we can constrain the focal mechanisms for two events: the 26 JUN 1924 earthquake at the northern end of the Hjort trench, and the 13 DEC 1960 earthquake south of the Puysegur trench.

A focal mechanism for the 1924 event is only possible because MACELWANE (1930) collected the seismograms for this event soon after its occurrence, he determined the instrument polarities, and published photographic reproductions of the seismograms with all pertinent information. RUFF and CAZENAVE (1985) plotted the $1924 P$ wave first motions on the focal mechanism for the nearby 2 AUG 1965 event to show that the 1924 faulting geometry differs from the strike-slip mechanism of the 1965 event (see Figure 26). The 1924 first motion data constrain one steeply dipping nodal plane to strike north. RUFF and CAZENAve (1985) speculated that the second nodal plane has a shallow dip to the east: the 1924 earthquake then represents underthrusting on a shallow dipping fault plane. Since the combination of right lateral strike-slip and underthrusting motion occurs elsewhere along the Macquarie Ridge, this interpretation seems reasonable. The 1924 event would then be the largest thrust event in the Macquarie Ridge complex.

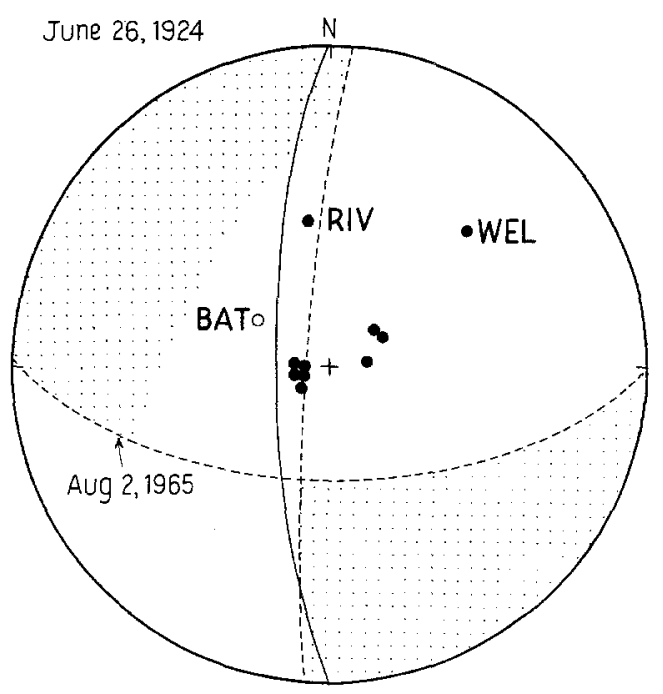

Figure 26

$P$ wave first motions for the $26 \mathrm{JUN} 1924$ earthquake. Most arrivals are compressional and plot near the center of the focal sphere. Compressional arrivals were also recorded in Australia (RIV) and New Zealand (WEL). There is a reliable dilatational arrival at Batavia (BAT). The first motion data constrain one of the 1924 nodal planes (solid line). The dashed nodal planes are for the 2 AUG 1965 event (see Table 1), the compressional quadrants are dotted. While the 1924 event appears to be a thrust event, the second nodal plane is poorly constrained and hence is not plotted. 


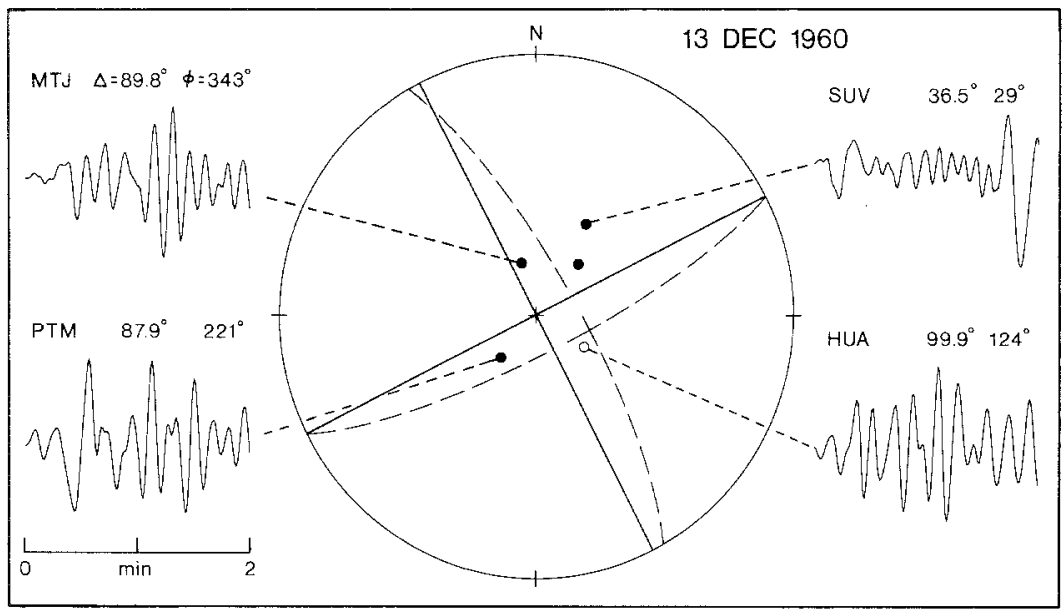

Figure 27

$P$ wave first motions and IGY long period seismograms for the 13 DEC 1960 earthquake. The 7 JUL 1982 focal mechanism is plotted as the dashed nodal planes. The solid lines show a pure strike-slip (right lateral) focal mechanism with the same fault strike as the 1982 event.

There were several experiments with globally deployed long-period seismographs before the WWSSN. The IGY seismograph program started operating in 1957. Many excellent long period seismograms were recorded, and the instrument polarities are generally well-known. Also, the seismology group at Lamont-Doherty Geological Observatory collected and archived most of the seismograms. We have obtained copies of these long-period records for the 13 DEC 1960 earthquake and are able to read several $P$ wave first motions. Figure 27 plots the 1960 first motion data, the nodal planes for the nearby 7 JUL 1982 earthquake, and a pure strike-slip mechanism with the same fault strike as the 1982 event. Note that the 1960 data do not allow the vertical fault plane to strike at $\mathrm{N} 30^{\circ} \mathrm{W}$, the trend for the large 1981 event to the north. Although the 1960 focal mechanism is not exactly the same as for the 1982 event, it seems that both earthquakes might share the same fault strike, and possibly the same fault plane.

\section{Discussion of Seismotectonics}

We now consider the seismotectonics of the Macquarie Ridge complex in light of the newly compiled results on several earthquakes. Two main questions are addressed: (1) does the PAC-AUS plate boundary coincide with the Macquarie Ridge complex, and if so, does the RM2 model adequately describe the PAC-AUS plate motions, and (2) is there a simple explanation for the seismicity pattern and varying focal mechanisms. 


\subsection{Plate Boundary Location and Plate Motion}

Although there is seismicity within the Australia plate between Balleny fracture zone and Puysegur trench, our interpretation is that these events are intraplate earthquakes and the PAC-AUS plate boundary coincides with the Macquarie Ridge complex from South Island to the triple junction at the southernmost end of the Hjort trench. Relative to the seismic activity along the MRC, the intraplate events in the Balleny-Puysegur trend are infrequent in number, smaller in size, and scattered in location with no consistent linear trend. In addition, the trend of the Balleny fracture zone south of $60^{\circ} \mathrm{S}$ is consistent with ANT-AUS plate motion and the relatively high level of seismic activity along the fracture zone indicates plate boundary slip. Thus, the narrow slice of oceanic lithosphere between Balleny fracture zone and the MRC (the "Tasman spur") moves as a rigid extension of the Australia plate.

5.1.1. BPF*: the PAC-AUS rotation pole. If the interaction between the Australia and Pacific plates along the Macquarie Ridge complex follows from rigid plate tectonics, then the instantaneous relative motions are described by rotation about a pole. Plate motion generally occurs as a combination of right lateral strike-slip and thrust events along most of the Macquarie Ridge, hence the net slip vector at a location should be a weighted average of the strike-slip and thrust vectors. It is difficult to specify the weighting of the two different slip directions as the recurrence intervals and fault area overlaps are not well determined. The motion in the southern Puysegur trench is clearly a mixture of strike-slip and thrust motion with slip azimuths of $\mathrm{N} 30^{\circ} \mathrm{E}$ and $\mathrm{N} 83^{\circ} \mathrm{E}$, respectively. The rotation pole should produce a slip vector orientation intermediate to these two directions. Therefore, the rotation pole should fall within the sector bounded by the two great circles that are normal to the strike-slip and thrust slip vector azimuths (see "pole lines" in Figure 28). Although there is a mixture of strike-slip and thrust earthquakes further south along the MRC, they are not spatially clustered as in the 1981 cluster. In the Macquarie Island region, we know the slip vector for the 1980 strike-slip earthquake. With the assumption that there is a missing thrust component, the rotation pole should lie south of the 1980 slip vector "pole line" (Figure 28). This restriction places the rotation pole south of the Minster and Jordan BFP. In a similar fashion, the 12 OCT 1979 thrust earthquake provides a further constraint, the rotation pole must lie to the east of the 1979 "pole line".

While the RM2 pole falls in the allowed sector in Figure 28, the Minster and Jordan BFP is clearly eliminated. Why does the RM2 pole better satisfy the expanded slip vector data set than the BFP pole? The BFP pole determination used only two events in the MRC, the $8 \mathrm{NOV} 1964$ event in the 1981 cluster and the 2 AUG 1965 strike-slip event at the northernmost Hjort trench that has the highest "importance" of any datum for the Pacific-India boundary (see MINSTER and 


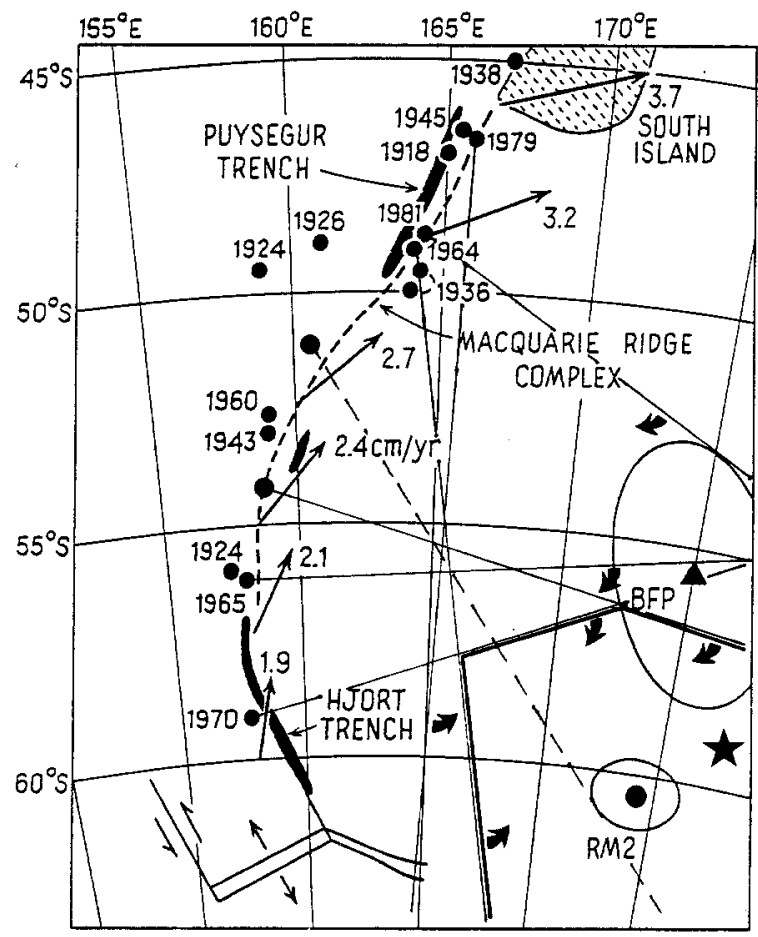

Figure 28

Slip vector constraints on the PAC-AUS rotation pole. Same as Figure 1 except that slip vector pole lines and BFP* have been added. Pole lines are perpendicular to earthquake slip vectors. The two pole lines from the 1981 cluster are from the strike-slip and thrust earthquakes, the rotation pole should lie between these lines, indicated by bold curved arrows. Other regions are characterized by either strike-slip or thrust events: the rotation pole should lie to the east of the thrust pole lines and south of the strike-slip pole lines. The best-fit rotation pole must then be located in the polygonal region bordered by the heavy line. The "true" PAC-AUS best-fit rotation pole (BFP*) is determined by the PAC-ANT and ANT-AUS best-fit rotation poles and is plotted as the star. The 7 JUL 1982 event pole line is dashed.

JORDAN, 1978, for discussion of "importance"). Indeed, notice that their BFP lies along the 1965 "pole line". We now realize that using only one event in a region of mixed focal mechanisms will bias the rotation pole, i.e., the rotation pole should not lie on the pole line from a single earthquake. The Minster and Jordan BFP is shifted to the final RM2 location by the constraint of triple junction closure. If the relative motion data for a plate boundary is biased, then a pole location based on triple junction closure could be more accurate. Of course, this assumes that the information for the other two plate boundaries is reliable. Since the PAC-ANT and ANT-AUS boundaries are both spreading centers with abundant transform faults and magnetic lineations, we would anticipate their relative motion to be well determined. Recall that the RM2 pole plotted in Figure 28 is actually the PacificIndia pole, and is determined by the RM2 poles for PAC-ANT and ANT-India. 
The internal deformation of the India plate causes the ANT-India RM2 pole to be displaced from the ANT-India BFP. Since the data for the ANT-India BFP determination are from the spreading system between Antarctica and Australia, the Minster and Jordan ANT-India BFP is the best representation of ANT-AUS plate motions. Thus, we construct the "best-fit" PAC-AUS rotation pole by applying triple junction closure to the Minster and Jordan BFP's for ANT-India and PAC-ANT. This "best-fit" PAC-AUS pole is referred to as BFP* and is plotted as the star in Figure 28. Note that it plots slightly to the north of the RM2 pole and is within the allowed sector. The fact that the location of BFP* is compatible with the new slip vector constraints supports the notion that the Tasman spur (lithosphere between Balleny fracture zone and MRC) is a rigid extension of the AUS plate. Recall that the 7 JUL 1982 event occurs at $51^{\circ} \mathrm{S}$ between the Puysegur trench and McDougall trough and has a slip vector azimuth that is intermediate to the strike-slip and thrust slip vector azimuths in the 1981 cluster. The slip vector pole line for the 1982 event lies to the south of BFP*. Hence the Puysegur trench and McDougall trough regions might be connected by a transform fault segment and the 1982 event occurs on the extension of this fault.

Returning to the plate boundary question, there is one caveat that we must mention. Plate motion is described by the rotation pole location and the rotation rate. Since we can only locate the position of the rotation pole with earthquake slip vectors, the Tasman spur could theoretically be a separate plate from the Australia plate. The two rotation poles, PAC-AUS and PAC-Tasman, could share the same location with respect to PAC. The Tasman spur could then be decoupled from the AUS plate by a transform fault along a small circle around their rotation pole. However, even if there is some deformation in the Tasman spur, we repeat our contention that the high level of seismic activity in the MRC indicates that most of the plate boundary slip occurs along the MRC. Thus, the Macquarie Ridge complex is the PAC-AUS plate boundary and the earthquakes are responding to present-day kinematic conditions.

\subsection{Oblique Subduction}

The MRC serves as the PAC-AUS plate boundary with a rotation pole close to RM2; the relative motion along most of the MRC is then characterized by oblique subduction. This oblique subduction is accommodated by a combination of two earthquake types: right lateral strike-slip motion on nearly vertical fault planes and thrust motion on fault planes with shallow dips. The primary example of this dual-rupture mode is the activity at the southern end of the Puysegur trench where the 1981 event occurred. The smaller thrust events have occurred along the entire rupture zone of the large 1981 strike-slip earthquake and these shallow dipping thrust planes are adjacent to the vertical strike-slip fault plane. This dual-rupture mode is unusual behavior. Oblique plate motion at other subduction zones is 
accommodated by earthquakes with oblique slip on a shallow dipping fault plane (for example: the Alaska-Aleutian subduction zone, WU and KANAMORI, 1973; the Japan subduction zone, KANAMORI, 1971; the Ecuador-Colombia subduction zone, KANAMORI and MCNALLY, 1982). We propose that the dual-rupture mode present in the MRC indicates an immature subduction zone, and is a simple consequence of transitional tectonics where the rotation pole is migrating at a geologically significant rate.

Plate tectonic reconstructions show that the PAC-AUS rotation pole has migrated south relative to the eastern part of South Island and the MRC, i.e., the Pacific plate (see Molnar et al., 1975). During this migration, the Puysegur trench region has been characterized by right lateral strike-slip motion, and possibly changed from a tensional to compressional environment. Thus, a long continuous vertical fault developed in this region and served as the primary locus of plate motion, just as the Alpine fault in South Island became a dominant tectonic feature. As the rotation pole migrated southward, the compressive component of motion became more significant and required some type of deformation. Horizontal shortening cannot be accommodated by slip on a vertical fault plane. New fault planes must develop if the deformation occurs by fault slip. In our interpretation, the small thrust events beneath the bathymetric rise in the 1981 cluster region represent slip on relatively new faults with a dimension of $20-50 \mathrm{~km}$. The three thrust focal mechanisms show different strikes and dips of the fault planes. These planes are not yet aligned as a smoothly continuous horizontal plane along the trench. Thus, these new fault planes cannot easily accommodate the strike-slip motion, and indeed the older vertical fault is still quite capable of that. As thrusting motion continues on the mosaic of new shallow-dipping fault planes, we speculate that they eventually coalesce into a single throughgoing shallow-dipping plate interface. At this point, the strike-slip component can then be accommodated by this fault surface with oblique slip. The role of the older strike-slip fault plane depends partly on where the new shallow-dipping fault forms. If the upper part of the strike-slip fault is on the plate that is overthrust, then it will be preserved and can even remain active. On the other hand, if the strike-slip plane is left on the plate that is underthrust, then it is subducted and disappears (see Figure 29). In our view, the accommodation of oblique subduction by large strike-slip and small thrust earthquakes is a temporary situation that is due to the recent transition to compression.

5.2.1. Tectonic analogy: San Andreas fault system. There is an analogous situation that has developed along the San Andreas fault system in California. One segment of the southern San Andreas is presently not aligned with the RM2 plate motions: the "great bend" segment in southern California that crosses the transverse ranges. There is a compressive component of motion across the strike of the San Andreas in this segment between Fort Tejon and San Gorgonio Pass. Two large 


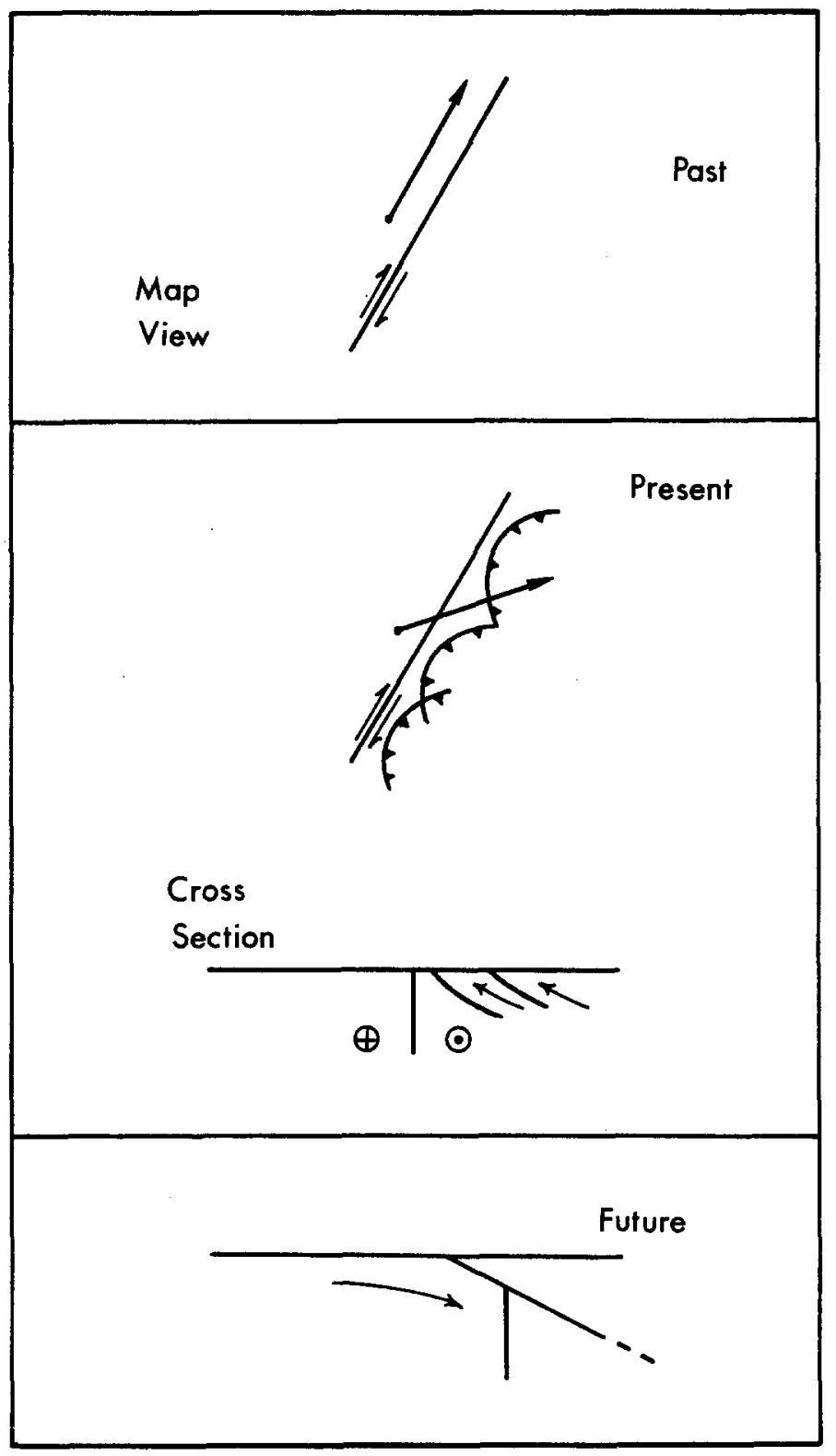

Figure 29

Transitional tectonics and dual-rupture mode. Schematic representation of the thrust interface development in the 1981 cluster region. Top diagram shows a vertical fault trace, the plate motion velocity vector (heavy arrow), and the subsequent right lateral strike-slip faulting. The middle diagram depicts the present-day situation in the 1981 cluster: the plate motion has shifted to oblique convergence and slip is also occurring on new small thrust faults. The thrust faults eventually coalesce into a throughgoing thrust interface (bottom diagram) that can accommodate oblique convergence. In the mega-crack propagation hypothesis, the transition from the middle to bottom diagram occurs in the crack-tip region that propagates along the plate boundary. 
shallow-angle thrust earthquakes have occurred along this segment, the 21 JUL 1952 Kern County and 9 FEB 1971 San Fernando events, adjacent to the San Andreas fault. Yet, the largest earthquake in this region is presumably the great strike-slip earthquake that occurred in 1857. Thus, the oblique convergence is accommodated by the dual-rupture mode as observed in the MRC. Although this analogy cannot be pressed too far, it points out that the situation in the southern Puysegur trench is not an isolated occurrence and may have quite general implications for other transitional tectonic environments. We will now return to the MRC and place the seismotectonics into a larger framework.

\section{Transitional Tectonics and Subduction Initiation}

There is a distinct discontinuity in the level of speculation between this section and the preceding sections of this paper. Since we will now extrapolate from the present-day tectonic picture and discuss the mechanisms of plate interaction, we must necessarily stray from our "factual" seismological realm. This paper would be incomplete without some discussion of this nature. The Macquarie Ridge presents us with a rare view of subduction initiation, hence we must take advantage of the opportunity and speculate on the underlying processes. Our approach will be to state an ad hoc "straw man" model for subduction initiation in the Puysegur trench environment. We then concentrate on the Hjort trench region and show that this environment is "controlled" by triple junction behavior, and we finish with a speculative account of the evolutionary history of the MRC.

\subsection{Puysegur Trench: Subduction Initiation}

The southward migration of the PAC-AUS rotation pole should impart a gradient in deformational style from mature to immature as we proceed from north to south. There is currently a compressive component of motion across South Island and the Alpine fault. It seems that this motion has been accommodated by broad-scale crustal shortening and mountain building (WALCOTT, 1978). The plate boundary switches to an oceanic-continental contact in the Fiordland region as the Alpine fault runs offshore. The intermediate-depth seismic activity beneath Fiordland presumably indicates that a relatively mature subduction environment now exists at the northern end of the MRC. Although a volcanic arc has not yet developed, perhaps the Solander cone just off the southern coast of South Island is a harbinger of future volcanism. If the Fiordland coast region is already characterized by subduction, the "leading edge" of subduction should be located to the south in the Puysegur region.

6.1.1. Mega-crack propagation model. Let us assume an initial plate boundary configuration of a well-developed pure transform boundary (such as in the top part 
of Figure 29). A mature subduction zone does not simply materialize just when the plate motion changes to a small compressive component along the established strike-slip trend. Based on our observations of the Puysegur trench seismotectonics, we propose a "straw man" model for subduction initiation that is akin to crack propagation: A "crack tip" region propagates along the plate boundary, and the velocity of propagation is similar to a plate tectonic rate. The primary function of the crack tip region is to organize the mosaic of small unconnected thrust fault planes into a large scale horizontally continuous shallow-dipping thrust interface. In front of the crack tip, oblique convergence is accommodated by strike-slip motion on the vertical fault and by lithospheric deformation along the strike slip boundary, possibly including small thrust earthquakes. Behind the crack tip, oblique convergence can be accommodated by oblique slip on the thrust interface, although the old vertical strike-slip fault may still be active. The final stages of competition and coalescence of the small thrust faults could lead to a locally high level of seismicity and, by analogy to crack propagation, the tectonic stress levels might be higher in the crack tip region which might cause high stress drop earthquakes. Note that the mega-crack propagation model implies that subduction does not initiate simultaneously along the entire length of the plate boundary.

Given the above model description, the 1981 cluster region is obviously identified as the crack tip region. A relevant observation is that the 1981 cluster is just south of the deepest portion of the Puysegur trench with a considerable reduction in bathymetric contrast along the 1981 fault zone. This offers some geometric support for the 1981 cluster representing the "tip of the crack" that is propagating south. After the crack extends, via the thrusting activity in the 1981 cluster, the underthrusting proceeds more easily and the bathymetric trough quickly extends southward. Hence subduction initiation is an "unzipping action" that may actually lower the tectonic stress level. This model predicts that the Puysegur trench to the north now has a continuous thrust interface. One possible explanation of the low seismicity level along the deepest part of the Puysegur trench might be a transition to aseismic slip after formation of the new underthrusting fault plane. Another more ominous explanation would be that this interface now ruptures as great underthrusting earthquakes with long recurrence time.

6.1.2. Objections to the mega-crack propagation model. We can immediately place some objections to the above simple model. One complication is the seismic activity at the northern end of the Puysegur trench. The mismatch between BFP* and the 1979 event pole line implies a missing strike-slip component of motion. If the region at $47^{\circ} \mathrm{S}$ is analogous to the 1981 region, then we should anticipate the occurrence of a large strike-slip earthquake in this region. The two focal mechanisms from the $47^{\circ} \mathrm{S}$ region show thrust motion, but note that previous to the 1981 event all mechanisms in the 1981 cluster were thrust mechanisms.

If we look at the detailed bathymetry in Figure 3, we notice that the 1979 event occurred just north of the deepest portion of the Puysegur trench: perhaps the 
trench is "propagating" both south and north. This ruins the idea that subduction initiation has smoothly propagated south from the Fiordland coast; rather there would be nucleation sites from which the mega-crack propagates in both directions. There is however a geometric problem if the 1979 region is the tip of a mega-crack. Intermediate depth seismicity under South Island presumably indicates that a substantial length of AUS plate has been subducted at Fiordland; how can we explain the presence of a crack-tip next to a region of plate subduction?

Another complication is related to the low seismicity region south of the 1981 cluster. The proposed fault plane of the 7 JUL 1982 earthquake can be extended from the 1982 epicenter to the $\mathrm{NE}$ along the fault strike of $\mathrm{N} 63^{\circ} \mathrm{E}$. This extension intersects the $25 \mathrm{MAY} 1981$ fault trend at $50^{\circ} \mathrm{S}$, just at the southern terminus of the 1981 seismicity cluster. Thus, the high level of seismicity in the 1981 cluster may not extend further south because the active plate boundary is offset by a transition region with a lower seismicity level. Thus, the 1981 cluster might be special because of the transition to the McDougall trough region, rather than for being at the southern tip of the Puysegur trench.

Further south along the MRC, we see the independent development of the McDougall trough with underthrusting to the west rather than to the east. Thus, the 1981 crack-tip may not be the unique locus of "unzipping" action. It is unknown whether the 1981 crack-tip can propagate south and switch the underthrusting polarity in the McDougall trough.

To conclude, the simple notion of a single crack-tip propagating southward certainly does not adequately explain all of the information. However, the evidence supports the basic premise that oblique subduction in a transitional environment is accommodated by the growth of new thrust faults. We cannot demonstrate that the mosaic of new thrust planes will eventually coalesce into a major throughgoing underthrusting boundary, but how else does a subduction zone form?

\subsection{Hjort Trench: Triple Junction Subduction}

The Hjort trench exceeds a depth of $6 \mathrm{~km}$ for nearly $300 \mathrm{~km}$ along an arcuate trend. There is no continuous major bathymetric rise associated with this trench, but the bathymetry is asymmetric about the axis: young lithosphere to the west is shallower than the older lithosphere to the east. This bathymetric difference is most pronounced at the southern end and disappears at the northernmost end of the Hjort trench. The trench shallows to the north where the 1924 and 1965 events occurred, and shallows to the south. It does not extend to the PAC-ANT-AUS triple junction. The only focal mechanism along the Hjort trench is for the 1970 earthquake, and this event is $350 \mathrm{~km}$ north of the triple junction. The basic level of seismicity is quite low between the 1970 event and the triple junction (see Figure 2).

The direct evidence for subduction along this trench consists of three parts: (1) the shorter length of the AUS magnetic lineations (WEISSEL et al., 1977), (2) character of the short-wavelength geoid anomalies, and (3) the speculative focal 
mechanism for the 1924 earthquake. Given our above conclusion that the PACAUS boundary follows the MRC, perhaps the most compelling evidence for subduction comes from considerations of the PAC-ANT-AUS triple junction. This leads into general discussion of the evolution of the MRC.

6.2.1. Triple junction closure. Triple junction closure and stability greatly influence plate interaction at the Hjort trench due to the proximity of the Hjort trench to the PAC-ANT-AUS triple junction. WeIsSEL et al. (1977) pointed out that the local condition of triple junction closure implies subduction along the Hjort trench. This approach leads to a prediction for the plate boundary geometry that can be tested.

Based on seismicity and bathymetric features, the PAC-ANT-AUS triple junction is located at $61.6^{\circ} \mathrm{S} 161^{\circ} \mathrm{E}$. One of the fundamental tenets of plate tectonics is triple junction closure. Moreover, the condition for triple junction stability places a constraint on the plate boundary interaction. We will consider local velocity vectors based on two different sets of rotation poles: (1) RM2 poles, and (2) the "true" best-fitting poles discussed above (Table 3). Since both sets have been derived with explicit use of the triple junction closure condition, it is no surprise that the local velocity vectors calculated for a location of $61.6^{\circ} \mathrm{S} 161^{\circ} \mathrm{E}$ sum to zero. We show the local velocity vectors for these two different pole sets in Figure 30. The PAC-AUS vector can be regarded as the difference between two larger and roughly parallel vectors. Hence, small changes in the PAC-ANT and the AUS-ANT velocity vectors result in relatively large changes for the PAC-AUS velocity vector. The north trending motion of AUS relative to PAC implies convergence across a northwest trending boundary. To see how the convergence occurs, we must use the condition for triple junction stability.

6.2.2. Triple junction stability. The condition for triple junction stability further constrains the plate boundary interaction. The ANT-AUS plate boundary is a spreading segment with approximately symmetric perpendicular spreading. While

Table 3

Velocity vectors at PAC-ANT-AUS triple junction for two rotation pole sets.

\begin{tabular}{|c|c|c|c|c|}
\hline \multirow{2}{*}{$\begin{array}{c}\text { Plate } \\
\text { Pair }\end{array}$} & \multicolumn{2}{|c|}{$\mathrm{RM} 2$} & \multicolumn{2}{|c|}{ BFP* } \\
\hline & Direction & Rate $\left(\mathrm{cm} \mathrm{y}^{-1}\right)$ & Direction & Rate $\left(\mathrm{cm} \mathrm{y}^{-1}\right)$ \\
\hline AUS-ANT & $\mathrm{S} 26^{\circ} \mathrm{E}$ & 6.20 & $\mathrm{~S} 28^{\circ} \mathrm{E}$ & 6.65 \\
\hline ANT-PAC & $\mathrm{N} 34^{\circ} \mathrm{W}$ & 4.82 & $\mathrm{~N} 35^{\circ} \mathrm{W}$ & 4.78 \\
\hline PAC-AUS & $\mathrm{N} 2^{\circ} \mathrm{W}$ & 1.55 & $\mathrm{~N} 10^{\circ} \mathrm{W}$ & 2.00 \\
\hline
\end{tabular}

Triple junction location is $61.6^{\circ} \mathrm{S} 161.0^{\circ} \mathrm{E}$. Velocity vectors give motion of the second plate relative to the first plate. 


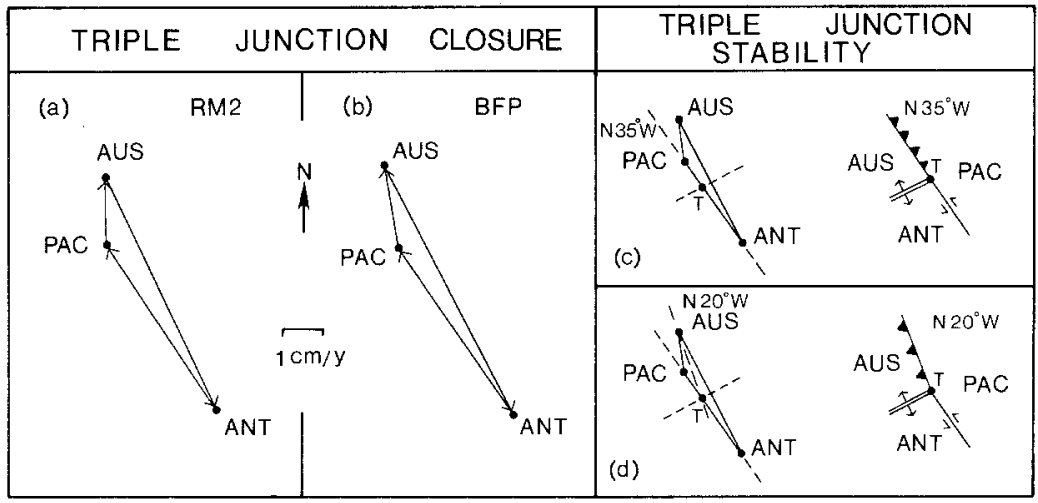

Figure 30

Triple junction closure and stability. For the PAC-ANT-AUS triple junction at $61 \frac{1}{2}^{\circ} \mathrm{S} 161^{\circ} \mathrm{E}$, (a) and (b) show the velocity vector closure for two sets of rotation poles, RM2 and BFP (listed in Table 3). Velocity scale and north arrow are shown. The BFP vector diagram is repeated in (c) and (d), north direction is the same but velocity vectors are drawn at half-scale. The triple junction point, $T$, must plot in velocity space along the dashed lines: (c) shows the case for AUS subducting beneath PAC with a subduction zone strike of $\mathrm{N} 35^{\circ} \mathrm{W}$, plate configuration is shown to the right; (d) shows the case for PAC subducting beneath AUS with a subduction zone strike of $\mathrm{N} 20^{\circ} \mathrm{W}$.

the PAC-ANT boundary might be a leaky transform, we will treat it as a pure transform for now. These two plate boundary descriptions place the intersection for a stable triple point along the PAC-ANT vector (Figure 30). There are two possible stable orientations for the subduction zone along the PAC-AUS boundary: (1) AUS subducts beneath PAC and the subduction zone strike is the same as the PAC-ANT transform strike, and (2) PAC subducts beneath AUS and the subduction zone strike is intermediate to the PAC-ANT transform and PAC-AUS plate motion strikes. Thus, a simple measurement of the local strike of the PAC-AUS plate boundary provides a strong check on the polarity of subduction. There is a problem however, the Hjort trench does not extend to the triple junction. There is a $200 \mathrm{~km}$ gap between the southernmost Hjort trench and the triple junction, and this region is devoid of well defined linear bathymetric features. Recall that the local strike of Hjort trench in the 1970 earthquake region is $\mathrm{N} 20^{\circ} \mathrm{W}$, and the Hjort trench strike clearly rotates to a more westerly strike to the south. Although it cannot be measured with great precision, it appears that the strike of the southernmost Hjort trench falls in the range of $\mathrm{N} 30-45^{\circ} \mathrm{W}$ as the trench curvature seems to increase as it shallows. A line between the triple junction and the 1970 earthquake location gives a strike of $\mathrm{N} 34^{\circ} \mathrm{W}$; this is in excellent agreement with the predicted value of $\mathrm{N} 35^{\circ} \mathrm{W}$ in Figure 30c. This interpolation implies that the present day plate motions are applicable over this $350 \mathrm{~km}$ projection of the plate boundary. Given the present-day migration rate of $1.5 \mathrm{~cm} / \mathrm{yr}$ for $T$ relative to PAC (see Figure $30 \mathrm{c}$ ), it would take more than $20 \mathrm{Ma}$ for the triple junction to migrate from the 1970 event 
location to its present position. The PAC-ANT rotation pole has shifted in this time period, thus the above correspondence may not be diagnostic of polarity. Another possible interpolation is over a $250 \mathrm{~km}$ projection to the southernmost tip of the Hjort trench; due to the curvature in the southernmost Hjort trench, this measurement gives a strike of $\mathrm{N} 20^{\circ} \mathrm{W}$. This latter measurement seems preferable to the former as the interpolation distance is smaller, but the consequence is that now the PAC plate subducts beneath the AUS plate! If this latter conclusion is true for the $250 \mathrm{~km}$ plate boundary segment adjacent to the triple junction, could the polarity of subduction then switch at the Hjort trench?

Before we make fine distinctions concerning the PAC-AUS plate boundary, we should consider the effect of a leaky transform along the PAC-ANT boundary. Although it is difficult to discern the plate tectonic elements just south of the triple junction, the low-level seismicity has a trend of about $\mathrm{N} 70^{\circ} \mathrm{W}$ over a distance of $300 \mathrm{~km}$. If we approximate the PAC-ANT boundary as a leaky transform with highly oblique spreading along this trend, the triple junction point in Figure 30c moves off the PAC-ANT velocity vector to a location slightly to the west. This causes the strike of the PAC-AUS subduction zone to rotate toward a more northerly strike; we could easily select the parameters to obtain a strike of $\mathrm{N} 20^{\circ} \mathrm{W}$ for the AUS plate subducting beneath PAC.

In conclusion, convergence is occurring along the PAC-AUS boundary north of the triple junction. Given the poor definition of both the PAC-AUS and PAC-ANT plate boundary segments, we cannot determine whether the AUS plate subducts beneath the PAC plate, or vice versa, or both. Thus it is difficult to decipher the nature of subduction initiation along the plate boundary segment between the triple junction and the southernmost Hjort trench. In any event, the aseismic nature of this segment implies that a mega-crack propagation model for subduction initation is not appropriate for this tectonic regime. The next section further examines the recent tectonic history of the Hjort trench by using additional information and arguments.

6.2.3. Triple junction evolution: southern Hjort trench. The triple junction stability condition can be used to obtain a view of the recent evolution of the triple junction region. As already mentioned, the average strike between the triple junction and the midpoint of the Hjort trench is $\mathrm{N} 34^{\circ} \mathrm{W}$, which is consistent with the AUS plate subducting at the Hjort trench. More evidence for the subduction of the AUS plate is based on evolution of the ANT-AUS spreading segment (see WEISSEL et al., 1977). Referring to the triple junction plots in Figure 30, it is clear that regardless of the details of the PAC-ANT and PAC-AUS boundaries, the ANT-AUS spreading ridge segment that lies between the Balleny fracture zone and the triple junction will become shorter with time, i.e., the $T$ point is to the west of the ANT-AUS velocity vector. Thus, the AUS plate created a few million years ago will have a greater length between the Balleny fracture zone and the plate edge than 
the present-day length of the spreading ridge segment. In fact, the width of the AUS plate measured perpendicular to the Balleny fracture zone decreases to a minimum value at the Hjort trench midpoint. This is not surprising given our previous measurement of a N34 $4^{\circ} \mathrm{W}$ trend from the triple junction to the Hjort trench midpoint while the Balleny fracture zone follows a trend of $N 22^{\circ} \mathrm{W}$. Part of the AUS plate is located to the east of the southern Hjort trench. Recall that the bathymetric difference across the southern Hjort trench indicates that the Hjort trench is the edge of the Pacific plate. Thus, part of the AUS plate has been subducted at the Hjort trench.

Triple junction interaction is important for the entire MRC, however the simple extrapolation used for the southern Hjort trench will not be valid further north due to significant changes in plate motions and geometry. We now discuss triple junction evolution over an extended time and distance; and thus enter a more speculative arena.

\subsection{Triple Junction Evolution: Origin of the Macquarie Ridge Complex}

We use three key assumptions to extrapolate the PAC-ANT-AUS triple junction interaction: (1) the AUS-ANT plate motion has remained relatively constant during the formation of the AUS plate along the MRC (i.e., the "Tasman spur"), (2) the PAC-ANT-AUS triple junction has continuously migrated southward from South Island to its present location, and (3) the present-day MRC records the geometry of the PAC-AUS plate boundary at the time of triple junction interaction. The first assumption is supported by the magnetic lineations as reported in WEISSEL et al. (1977). Thus, the ANT-AUS velocity vector remains constant while the other two vectors vary with time (see Figure 31). Assumptions (2) and (3) arise from considerations of the plate geometry and triple junction closure diagram. If the PAC-ANT and ANT-AUS velocity vectors trend in the same basic direction, then the triple junction will migrate south relative to the PAC plate if the PAC-ANT rate is more than about half the ANT-AUS rate at the triple junction. Also, the sense of strike-slip displacement component along the PAC-AUS boundary will be right lateral as long as the PAC-ANT rate $\left(r_{\mathrm{PAC}-\mathrm{ANT}}\right.$, magnitude of the PAC-ANT velocity vector at the triple junction) is less than the ANT-AUS rate $\left(r_{\text {ANT-AUS }}\right.$, similar definition $)$. Thus, by imposing the rate constraint: $\frac{1}{2}<\left(r_{\mathrm{PAC}-\mathrm{ANT}} /\right.$ $\left.r_{\text {ANT-AUS }}\right)<1$, we ensure the southern migration of the triple junction with respect to PAC, and right lateral strike-slip along the MRC.

Whether the PAC-AUS boundary has a convergent or divergent component depends on whether the PAC-ANT vector strikes to the east or west of the ANT-AUS vector. Figure 31 shows the field of allowed PAC-ANT velocity vectors. To obtain the location of the triple junction point in velocity space, we must make assumptions concerning the nature of the PAC-ANT and PAC-AUS plate boundaries. We assume that the PAC-ANT plate boundary has been a transform or 


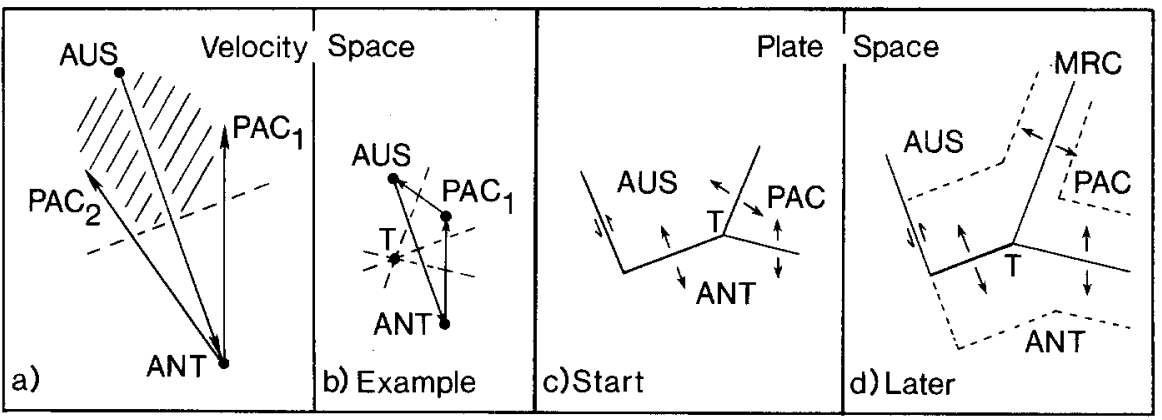

Figure 31

Triple junction evolution and Macquarie Ridge formation. Diagram on left (a) is a velocity vector diagram for the PAC-ANT-AUS triple junction. ANT-AUS plate motion is taken to be constant throughout Macquarie Ridge formation. The PAC-ANT vector can plot anywhere in the hatched region, two possible vectors are drawn $\left(\mathrm{PAC}_{1}\right.$ and $\left.\mathrm{PAC}_{2}\right)$. The PAC-AUS velocity vector is then determined as the difference vector. The PAC-AUS boundary is a "soft" boundary that accommodates the mismatch between the ANT-AUS and PAC-ANT motions. If the PAC-ANT vector plots to the east of the ANT-AUS vector (e.g., PAC $_{1}$ ), then the PAC-AUS boundary will have a divergent component (b). The diagrams to the right (c and d) depict the evolution of the triple junction region for this example. Note that the PAC-AUS boundary is a leaky transform that strikes N-NE and that the ANT-AUS spreading segment shortens with time. The basic geometry of the Macquarie Ridge plate boundary (MRC) can be explained by triple junction evolution changing the PAC-AUS boundary from a divergent state to the present-day convergent state (e.g., PAC $_{2}$ ). This switch occurs as the PAC-ANT velocity vector slowly rotates to a more westerly strike, relative to ANT-AUS motion, at the migrating triple junction.

a leaky transform. Note that most of the MRC lies just west of the Campbell plateau, and it therefore seems unlikely that a major PAC-ANT spreading segment has occupied the space between the MRC and the Campbell plateau. The basic geometry of the MRC can be produced by assuming that the PAC-AUS boundary was originally in a divergent state (as suggested by MoLNAR et al., 1975), and the PAC-ANT velocity vector slowly rotated to impart a convergent component. For the divergent MRC environment, we can always find a combination of leaky transforms for the PAC-AUS and PAC-ANT boundaries that give a stable triple point. Given the erosion of the ANT-AUS spreading segment through time, the triple point should be located to the west of the ANT-AUS vector. Leaky transforms along the PAC-AUS and PAC-ANT boundaries could feed off the primary ANT-AUS spreading segment. As shown in Figure 31, the PAC-AUS leaky transform can strike to the northeast, i.e., the trend for the present-day northern and central MRC. Recall that the local strike of the Hjort trench in the 1970 region is about $\mathrm{N} 20^{\circ} \mathrm{W}$; this could mark the location of the triple junction at the crossover time when the PAC-ANT velocity vector rotated to the west of the ANT-AUS vector at the triple junction. After the crossover time, the plate boundary segment immediately north of the triple junction would be a convergent boundary. This implies that only the southern Hjort trench region was formed originally as a 
convergent plate boundary, while the other parts have evolved from a leaky transform to a convergent region. This lends circumstantial support to the notion that the small thrust faults in the northern MRC represent new breaks in the lithosphere.

\subsection{Macquarie Ridge Complex: A "Soft" Plate Boundary}

The MRC plate boundary has evolved at the junction of two major spreading systems. The PAC-ANT spreading system reorganized when Australia rifted from Antarctica. In particular, the Tasman Sea spreading stopped, and the PAC-ANT system linked up with the AUS-ANT system. These two spreading systems are not perfectly "matched" in terms of their spreading direction and rate. The PAC-AUS boundary along the MRC has served to accommodate this mismatch.

To take a more global view, the major spreading systems are currently connected as a single sinuous strand. However, many of these spreading systems originally developed somewhat independent of each other. If the major spreading systems retain their rotation poles, i.e., their fracture zones fall along consistent small circles, then there must be some conflict in the local plate motions at the junction between two of these spreading systems. A third plate boundary is clearly required at this junction; this third boundary is a "soft" boundary in that it accommodates the mismatch in the motion of the other two spreading center boundaries. The motion across the "soft" boundary changes as necessary for triple junction closure and stability (see Figure 32). In general, the velocity vectors for the

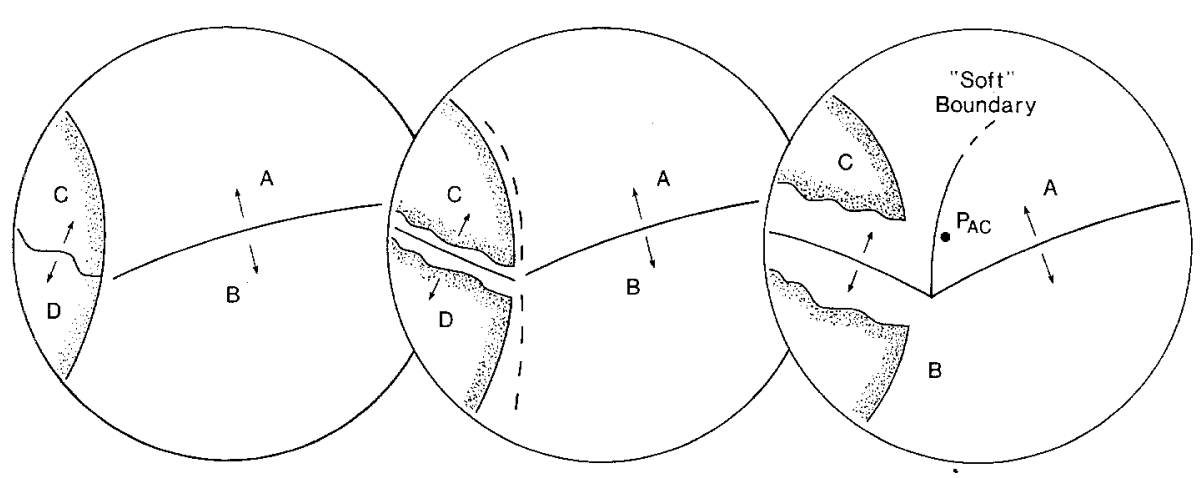

Figure 32

Schematic development of a "soft" plate boundary to accommodate mismatch between two major spreading systems. The diagrams sketch the global-scale tectonic features at three stages. The initial situation is depicted at left, one oceanic spreading system separates plates $A$ and $B$, while the other system will fragment the continent into plates $C$ and $D$. At a later time in the middle diagram, the continent has fragmented but the connection between the two systems is immature, perhaps there are still four plates with two auxiliary plate boundaries (dashed). In the evolved three-plate configuration at right, plates $B$ and D are now fused, and the two major spreading systems continue their activity with the "soft" boundary absorbing the mismatch. The rotation pole $\left(\boldsymbol{P}_{\mathrm{AC}}\right)$ for the "soft" boundary is located close to the triple junction. Subduction initiation can easily occur along the "soft" plate boundary. 
two spreading boundaries at the triple junction will change with time. Thus, the "soft" velocity vector must be capable of changing to keep up with the evolution. If the velocity vectors (at the triple junction) for the two major boundaries are almost "matched", i.e., nearly parallel with comparable rates, then the magnitude of the velocity vector for the "soft" boundary is small and the direction of motion may change rather quickly. The "soft" boundary can easily serve this function if its rotation pole follows close to the triple junction. In this case, small changes in the pole location can readily change the direction of the velocity vector at the triple junction, yet these pole changes will not greatly affect the tectonic environments far from the triple junction along the "soft" boundary, e.g., for the case of the PAC-AUS "soft" boundary, we do not want to switch from subduction to spreading at the Kermadec trench in a few million years. Thus, the migration of the PAC-AUS rotation pole is simply a consequence of the pole following the triple junction as it migrates south.

Subduction initiation at the triple junction has occurred along the southernmost Hjort trench simply because the slow migration of the triple junction and the PAC-ANT pole places the "soft" PAC-AUS boundary in a convergent state at the triple junction. Subduction initiation to the north at the Puysegur trench is due not only to the migration of the PAC-ANT pole relative to the PAC-AUS pole, but also to the northward transport of the Puysegur trench region by the spreading systems.

6.4.1. Predictions for other "soft" plate boundaries. The above described circumstances that require a "soft" boundary are quite general. Hence we expect to see other "soft" plate boundaries as offshoots along the major spreading systems. Given a triple junction with at least two spreading segments, our prediction is that the rotation pole for the "soft" boundary should be located close to the triple junction. Indeed there are several candidates for "soft" boundaries: the EurasiaAfrica plate boundary may be the "soft" boundary between the north and central Atlantic spreading segments; the Nazca-Cocos plate boundary may be a "soft" boundary for the Pacific spreading ridge; and the India-Arabia plate boundary may be the "soft" boundary for spreading systems in the Indian Ocean and Gulf of Aden. The implication is that the connection and evolution of the major spreading systems can generate secondary spreading segments or initiate subduction as the need arises. Placed in this context, subduction initiation does not present a major obstacle to plate boundary evolution. Perhaps an efficient mechanism such as mega-crack propagation makes subduction initiation a common tectonic process. A newly initiated subduction zone can develop into a major subduction zone as it continues to move away from the triple junction. Perhaps there is a threshold at which the new subduction zone changes from a "soft" to "hard" boundary. 


\section{Conclusions}

It is difficult to simply list the conclusions of this paper due to the gradient in scientific style from our detailed investigation of the 1981 earthquake to our global-scale speculations. Hence, we group our primary conclusions into three categories: strong, moderate, and weak.

Strong conclusions: The PAC-AUS plate boundary coincides with the MRC. Our study of the largest earthquakes in the MRC finds a combination of right lateral strike-slip and thrust earthquakes along the MRC, and the overall sense of motion is consistent with the BFP* rotation pole located on the basis of triple junction closure with the well determined BFP's for the PAC-ANT and AUS-ANT plate boundaries. Oblique convergence in the southern Puysegur trench is accommodated by a dual-rupture mode: a large strike-slip earthquake on vertical fault plane and smaller thrust earthquakes on shallow-dipping fault planes that are not continuous.

Moderate conclusions: A subduction initiation model applicable to the Puysegur trench region uses the basic idea of a propagating crack. The crack tip region separates a disjointed mosaic of small thrust faults in front of the crack tip from a through-going single thrust interface behind the crack tip. The 1981 cluster is identified as the crack tip region. The tectonics in the Hjort trench region are dominated by triple junction behavior and the PAC-AUS boundary to the north of the triple junction presently evolves as a convergent boundary. The subduction initiation process with newly created lithosphere is apparently aseismic.

Weak conclusions: The MRC is a "soft" plate boundary that accommodates the mismatch between the PAC-ANT and ANT-AUS spreading ridge systems. Soft boundaries are necessary to connect the major spreading systems. Apparently, two spreading systems can easily initiate a new subduction zone.

Many of our interpretations are based on the basic principles of plate tectonics. It is well-known that: triple junctions will evolve; rotation poles migrate in a three-plate system; and that subduction initiation must somehow occur. The novelty of our development is not in the description of a specific history for the MRC, but rather in the speculation on the controlling factors and processes. For example, we have ventured beyond the kinematic fact that subduction initiation must occur and have proposed the mega-crack propagation model to initiate subduction. In addition, the concept of a "soft" third boundary to help connect two major spreading systems implies that new subduction zones can be readily created by the "hard" boundaries of major spreading systems. The interpretations and conclusions of this paper are nonunique; different investigators may use the same information presented above and arrive at different conclusions. However, the importance of the MRC tectonic setting will remain. The Macquarie Ridge complex displays spatial and temporal gradients of plate boundary interaction, and thus represents a natural laboratory for the study of plate boundary evolution and subduction initiation. 


\section{Acknowledgments}

Several people have contributed materials for this project: H. Eissler, L. Stewart, and W. Smith, in particular. Les Thurston drafted several figures. We benefited from discussions with Hiroo Kanamori and Anny Cazenave. Special thanks to Melissa Schell for her help in the final stages of figure and manuscript preparation. This project has been supported by grants from the National Science Foundation: initially to Prof. Kanamori at Caltech and then later to L. J. R. at the University of Michigan (EAR8351515 and EAR8407786). Also, a grant from the Shell Companies Foundation has helped the completion of this project.

Seismicity Update: Another magnitude 7 event has occurred in the MRC: 3 SEP $1987,6: 40: 13.9,58.9^{\circ} \mathrm{S} 158.5^{\circ} \mathrm{E}, M_{s}=7.3$. This location is quite close to the 1970 Hjort trench event. The best double couple from the Harvard CMT solution has a fault strike of $155^{\circ}$, dip of $69^{\circ}$, and rake of $188^{\circ}$-right lateral strike-slip along a trend of $\mathrm{N} 25^{\circ} \mathrm{W}$, close to the $\mathrm{N} 14^{\circ} \mathrm{W}$ fault strike of the 1970 event. The Harvard CMT solution for a large $\left(M_{s}=6.8\right)$ aftershock shows a substantial thrust component-another example of the curious dual rupture mode along the MRC.

\section{REFERENCES}

BANGHAR, A. R. and Sykes, L. R. (1969), Focal mechanisms of earthquakes in the Indian Ocean and adjacent regions, J. Geophys. Res. 74, 632-649.

BECK, S. L. and RUFF, L. J. (1984), The rupture process of the great 1979 Colombia earthquake: Evidence for the asperity model, J. Geophys. Res. 89, 9281-9291.

BECK, S. L. and RUFF, L. J. (1985), The rupture process of the 1976 Mindanao earthquake, J. Geophys. Res. 90, 6773-6782.

BECK, S. L. and RUFF, L. J. (1987), Rupture process of the great 1963 Kurile Islands earthquake sequence: Asperity interaction and multiple event rupture, J. Geophys. Res. 92, 14,123-14,138.

Ben-MenAhEM, A. (1961), Radiation of seismic surface waves from finite moving sources, Bull. Seism. Soc. Am. 51, 401-435.

CHRISTEnsen, D. H. and RufF, L. J. (1985), Analysis of the trade-off between hypocentral depth and source time function, Bull. Seism. Soc. Am. 75, 1637-1656.

DEWEY, J. W. and SPENCE, W. (1979), Seismic gaps and source zones of recent large earthquakes in coastal Peru, PAGEOPH 117, 1148-1171.

Dziewonski, A. M., Chou, T., and Woodhouse, J. H. (1981), Determination of earthquake source parameters from waveform data for studies of global and regional seismicity, J. Geophys. Res. 86, 2825-2852.

DzIEWONSKI, A. M. and WoOdHouse, J. H. (1983), An experiment in systematic study of global seismicity: CMT solutions for 201 moderate and large earthquakes of 1981, J. Geophys. Res. 88, $3247-3271$.

GUtenberg, B. and Richter, C. F., Seismicity of the Earth (Princeton University Press, 1949).

Johnson, T. and Molnar, P. (1972), Focal mechanisms and plate tectonics of the southwest Pacific, J. Geophys. Res. 77, 5000-5033.

KANAMORI, H. (1971), Focal mechanism of the Tokachi-Oki earthquake of May 16, 1968: Contortion of the lithosphere at a junction of two trenches, Tectonophysics 12,1-13. 
KANAMORI, H. (1977), The energy release in great earthquakes, J. Geophys. Res. 82, 2981-2987.

KANAMORI, H. and ANDERSON, D. L. (1975), Theoretical basis of some empirical relations in seismology, Bull. Seism. Soc. Am. 65, 1073-1095.

KANAMORI, H. and GIVEN, J. W. (1981), Use of long-period surface waves for rapid determination of earthquake source parameters, Phys. Earth Planet. Int. 27, 8-31.

KANAMORI, H. and MCNALlY, K. (1982), Variable rupture mode of the subduction zone along the Ecuador-Colombia coast, Bull. Seism. Soc. Am. 72, 1241-1253.

Kanamori, H. and Stewart, G. S. (1978), Seismological aspects of the Guatemala earthquake of February 4, 1976, J. Geophys. Res. 83, 3427-3434.

LYNNES, C. S. and RuFF, L. J. (1985), Source process and tectonic implications of the great 1975 North Atlantic earthquake, Geophys. J. R. Astr. Soc. 82, 497-510.

Macelwane, J. B. (1930), The south Pacific earthquake of June 26, 1924, Beitr. Geophys. 28, 165-227.

MAMmericks, J., SMITH, S. M., TAYlor, I. L., and ChASE, T. E. (1975), Topography of the South Pacific (Scripps Institute of Oceanography, La Jolla, CA).

Minster, J. B. and Jordan, T. E. (1978), Present-day plate motions, J. Geophys. Res. 83, 5331-5354.

Molnar, P., Atwater, T., Mammericks, J. and SMith, S. M. (1975), Magnetic anomalies, bathymetry, and the tectonic evolution of the south Pacific since the late Cretaceous, Geophys. J. R. Astr. Soc. 40, 383-420.

PAGE, R. (1973), The Sitka, Alaska earthquake of 1972: An expected visitor, Earthquake Information Bull. 5, 4-9.

PlAFKeR, G. (1976), Tectonic aspects of the Guatemala earthquake of 4 February 1976, Science 193, 1201-1208.

PurCaru, G. and BerCKHemer, H. (1982), Quantitative relations of seismic source parameters and a classification of earthquakes, Tectonophysics $84,57-128$.

RUFF, L. J. (1983), Fault asperities inferred from seismic body waves, In Earthquakes: Observation, Theory, and Interpretation (ed. Kanamori, H. and Boschi, E.) (North-Holland, Amsterdam) pp. 251-276.

RufF, L. and CAzenave, A. (1985), SEASAT geoid anomalies and the Macquarie Ridge complex, Phys. Earth Planet. Int. 38, 59-69.

RUFF, L. and KANAMORI, H. (1983), The rupture process and asperity distribution of three great earthquakes from long-period diffracted P-waves, Phys. Earth Planet. Int. 31, 202-230.

SCHELl, M. M. and RufF, L. J. (1988), Rupture of a seismic gap in southeastern Alaska: The 1972 Sitka earthquake $\left(M_{s} 7.6\right)$, Phys. Earth Planet. Int., in press.

SCHOlz, C. H., RYNN, T. M., WeEd, R. W., and Frohlich, C. (1973), Detailed seismicity of the Alpine fault zone and Fiordland region, New Zealand, Geol. Soc. Am. Bull. 84, 3297-3316.

SCHWARTZ, S. Y. and RufF, L. J. (1985), The 1968 Tokachi-Oki and the 1969 Kurile Islands earthquakes: Variability in the rupture process, J. Geophys. Res. 90, 8613-8626.

STEIN, S. and OKAL, E. A. (1978), Seismicity and tectonics of the Ninetyeast Ridge area: Evidence for internal deformation of the Indian plate, J. Geophys. Res. 83, 2233-2245.

SYKES, L. R. (1967), Mechanisms of earthquakes and nature of faulting on the midocean ridges, J. Geophys. Res. 72, 2131-2153.

WalcotT, R. I. (1978), Present tectonics and late Cenozoic evolution of New Zealand, Geophys. J. R. Astr. Soc. 52, 137-164.

WARD, S. (1979), Ringing $P$ waves and submarine faulting, J. Geophys. Res. 84, 3057-3062.

Wiens, D. A. DeMets, C., Gordon, R., Stein, S., Argus, D., Engeln, J., Lundgren, P., Quible, D., STEIN, C., WeINSTEIN, S., and WoODS, D. (1985), A diffuse plate boundary model for Indian Ocean tectonics, Geophys. Res. Lett. 12, 429-432.

Weissel, J. K., HAyes, D. E., and Herron, E. M. (1977), Plate tectonics synthesis: The displacements between Australia, New Zealand, and Antarctica since the late Cretaceous, Marine Geol. 25, 231-277.

Wu, F. T. and KANAMORI, H. (1973), Source mechanism of February 4, 1965, Rat Island earthquake, J. Geophys. Res. 78, 6082-6092. 